XVI.

\title{
Ueber die Wirkung des Fäulnissprocesses auf den lebenden Organismus \\ ron
}

Dr. S. Samuel

in Königsberg.

Die souveräne Herrschaft, welche der Fäulnissprocess tiber jede todte organische Substanz ausübt, deren er habhaft werden kann, lässt seinen Einfluss auf den lebenden Organismus als eine Cardinalfrage der Biologie betrachten. Ist die Fäulniss eine Arbeitsleistung der kleinsten organischen Wesen, der Bacterien, so wird es allein der Untersuchung am lebenden Thiere beschieden sein, mit Sicherheit festzustellen, unter welchen Umständen die Ansiedlung und Vermehrung der Fäulnissbacterien im lebenden Organismus stattfinden kann und inwieweit sie, einmal angesiedelt, gleiche Wirkung auf Leben wie auf Tod auszuüben vermögen.

Dies ist an sich ein Gegenstand von so eminenter physiologischer Wichtigkeit, dass pathologische Erwägungen das Interesse nur zu verbreitern, aber nicht mehr zu vertiefen vermögen. Unbeachtet fuir die Fragestellung wird aber gewiss nicht der Gesichtspunkt bleiben dürfen, dass von allen pathogenen Bacterien, welche lebendige Träger der Contagien zu sein angeschuldigt werden, kaum andere in gleich umfassendem Úmfange zur Untersuchung gestellt werden können. Denn was der Entzündungsprocess für die Ernährungsstörungen ist, ist der Fäulnissprocess für die Infectionslehre, der feste experimentelle Halt, der sichere Boden, von dem aus die Forsehung in bisher unbetretene Regionen vorzudringen vermag.

Vor längerer Zeit bereits, als ich am Kaninchenohre die verschiedensten Formen der Entzündung in beweiskräftigen Bildern hergestellt, trieb es mich, zu versuchen, ob sich nicht an demselben Objecte auch etwas Charakteristisches für den Fäulnissprocess ge- 
winnen liesse. Was ich fand (Vorläufige Mittheilung. Centralblatt 1871 Nro. 20) war ermuthigend genug; um am lebenden Thiere den Process weiter und weiter zu verfolgen. Weiter in dem Sinne, dass ich bald erkannte, als ein wie feines Reagens das Ohr auch hier sich wieder bewährt, - doch aber als ein zu feines, um schlechthin als musterguiltiges dastehen zu können. Dies führte zu einer Vervielfältigung der Angriffspunkte, zur Würdigung der localen Verhältnisse. Weiter aber auch in einem ganz anderen Sime. So lange die Fäulniss als ein rein chemischer Vorgang galt, durfte man darauf rechnen, dass die Wirkung der Stärke des Giftes adäquat, intensive Fäulnissvorgänge also nur durch starke Fäulnissgifte hervorgebracht werden können. Diese Vorstellung schloss die Consequenz in sich, dass die Fäulniss nicht jederzeit gleich verderbliche Producte erzeugen werde und dass die schlimmsten selbst durch Dilution eine Linderung erfahren können. Dieser ganze Ideenkreis, der ein relatives Sicherheitsgefühl der Sepsis gegeniiber zu erzengen vermochte, wurde durch den Bacterienursprụng der Fäulniss aufs Tiefste erschüttert. Angesichts der perniciösesten Färlnissprocesse im Körper musste man sich sagen: Wie? Und solche Processe sollen das nothwendige Product einer jeden grösseren oder geringeren Anzahl von Fäulnissbacterien werden, die durch irgend eine offene Wunde Gelegenheit gefunden haben, einzudringen, sich anzusiedeln und in infinitum zu vermehren? Nur unseres Hautschutzes brauchen wir beraubt zu sein, um im Leben schon hülflos ihnen preisgegeben zu sein? Und wie leicht können sie die Gelegenheit finden, ihr Parasitendasein schon im lebenden Körper fortzusetzen! Denn diese unsere Todfeinde sind rings um uns, in der Luft, im Wasser. Wenn auch von der Luft aus die Inficirung weit langsamer geschieht, als durch Wasser und unreine Oberflächen (Burdon-Sanderson), so führt doch der Staub nebst grösseren Körpern auch frïher oder später Bacterien ein. Noch mehr Gefahr droht aber von jedem Wasser, denn, wenn sie sich auch oft nur in geringer Zahl und obne Vermehrung in Ruhe oder Dauerzellenzustand darin befinden, so gerathen doch diese Keime in Vegetation und vermehren sich ins Unendliche, sobald sie geeignete Nahrung finden. (Ferdinand Cohn, Untersuchungen iuber Bacterien im 2. Heft seiner Beiträge zur Biologie der Pflanzen 1872). Geeignete Nährfliissigkeit aus Wasser, Salzen, Stickstoff ist aber im thierischen Körper in tippiger Fuille, die hohe Temperatur muss zudem das Wachsthum beschleunigen. $\mathrm{Zu}$ welchen Massen sich unter günstigen Umständen diese kleinsten aller Wesen entwickeln können, ist nicht blos Gegenstand 
sinnreicher Berechnungen gewesen, sondern bereits Object der Technik bei der Production von Hefezellen. In Betreff der Fäulnissbacterien zeigt aber jeder faulende Eiweissklumpen, wie rasch deren Vermehrung bis zu unzählbaren Milliarden vor sich geht.

Verhängnissvolle Aussichten! - Kein Zweifel jedoch, iibten diese Wesen gleiche Herrschaft auf Leben wie auf Tod, des Menschen Kampf um das Dasein wäre ein sehr schwieriger, die Kriege zum Mindesten hätten längst mit stumpfen Waffen geführt werden mïssen.

Offenkundige Thatsachen widerstreben doch dieser ganzen Vorstellung. Es ist allbekannt, dass eine áusgebildete Sepsis, alle Wunden ineinander gerechnet, doch relativ sehr selten ist. Sie kommt vor. Eben, dass Wundfäulniss vorkommi, beweist ebenso unwiderlegbar die Möglichkeit der intensivsten Fäulnissprocesse am lebenden Körper, wie deren relative Seltenheit die Wirksamkeit beschränkender Bedingungen nachweist. So stehen wir hier vor einem Gegensatze zwischen Theorie und Thatsache, den das Experiment allein zu schlichten vermag.

$\mathrm{Zu}$ den von Alters her anerkannten septischen Vorgängen hat man jedoch neuerdings noch ganz anderen Krankheiten einen septischen Ursprung zugeschrieben. Seit längerer Zeit bereits wird fiir das Erysipel mit ebenso grosser Bestimmtheit der. Satz behauptet als bestritten, dass es einfach putride Stoffe oder die Secrete sind, die sich unter gewöhnlichen Verhältnissen 'an eiternden' und jauchenden Wunden bilden, welche dieses Gift für sich allein constituiren. Der Beweis fehlte, denn wenn wir bei Thierexperimenten Eiter; Jauche und putride Fliussigkeiten unter die Haut injiciren, so bekommen wir oft genug acute, rasch über eine ganze Extremität sich ausbreitende Eiterungen oder Verjauchungen des Zellgewebes, nie aber ein einfaches, legitimes Erysipel. (Volkmann, Erysipelas, Rose etc. S. 132). Man wird nicht sagen können, dass diese Aufgabe in der nenesten Arbeit von Orth über das Erysipel gelöst ist, denn auch er hat nicht das einfache legitime Erysipel erzeugt, sondern jenes Erysipelas malignum, dessen ätiologischer Connex mit dem Erysipelas simplex eben erst zu beweisen sein wird. Er hat sich aber auch gar nicht einmal die Aufgabe in unserem Sinne gestellt, sondern glaubte in der fortpflanzungsiähigen Wirksamkeit des Inhalts einer Erysipelblase ein specifisches Erysipelasgift zu erken. nen, „welches die Fäulniss nicht im Stande ist, völlig zu vernichten, sondern nur abzuschwächen" (Orth, Untersuchungen uiber das Erysipel. Dieses Archir Band I. S. 81 u. folgende). Ja er 
er beweist die Specifität eben dadurch, dass er in den mit gleichen Mengen putrider oder bacterienhaltiger Flüssigkeit angestellten Controllversuchen bis jetzt keine ähnlichen Symptome erzielen konnte. Danach wäre also das Erysipelas malignum keine septische, sondern eine specifische Mykose, das Erysipelas simplex aber ätiologisch noch gar nicht erkannt.

Aber noch ganz andere und viel ausgedehntere Wirkungen sind neuerdings der Sepsis zugeschrieben worden. Die Beobachtung, dass die Continuitätstrennungen der inneren Organe (Gehirn, Lunge, Leber, Darm), "mögen sie durch das Projectil oder indirect durch Sprengung losgelöster Körpertheile oder losgerissener Fremdkörper bedingt sein, keine entzündlichen Veränderungen nach sich ziehen, ja, dass die reparativen Neubildungsprocesse in ihnen oft nicht den Umfang erreichen, um die Schusskanäle zum Verschluss zu bringen, hat Klebs und Socin (Beiträge zur Anatomie der Schusswunden) zu der Idee geführt: auch getödtete Theile brauchen nicht zu eitern, sie können langsam moleculär zerfallen, und allmälig resorbirt werden; wenn sie also eitern, ist nicht das Absterben, sondern das Abfaulen der Grund der Eiterung.

Gedenken wir noch der andern zahlreichen Fälle, "wo das Auffinden von Sporen in Krankheitsherden, das Nebeneinander in der Leiche zu dem Schlusse eines ursächlichen Zusammenhanges geführt hat (der Pneumomykosen, Dermatomykosen), der zahlreichen Krankheiten ferner, die durch verschiedene andere Bacterienarten erzeugt sein sollen, der Diphterie, des Milzbrandes, Pocken, Scharlach, Masern, Cholera ete., so können wir nicht zweifeln, dass wir an der Schwelle einer Aera des Bacterien-Contagiums stehen. Die Lehre vom Contagium vivum hat schon öfter in der Medicin Glauben gefunden und bereits zu Leeuwenhoek's Zeiten hat der stets sehr rege Ideenflug der Aerzte das Räthsel der Epidemien durch mikroskopische Pestfliegen erklären zu können geglaubt. Soll also der durchaus berechtigte hoffunngsvolle Gedanke fruchtbringend werden für unsere Naturerkenntniss, soll er nicht an seiner eigenen Schrankenlosigkeit scheitern, so gilt es - für unsere Aufgabe zunächst festzustellen, nicht blos, welche Krankheiten durch die septische Mykose erzeugt werden können, sondern vor allem, unter welchen Umständen so verschiedenartige Wirkungen, wie Septicämie und gutartige Eiterung, Jauchung und einfaches Erysipel, durch dieselbe Ursache erzeugt werden, vorausgesetzt, dass dies iiberhaupt der Fall ist.

Dies die Aufgabe. Ehe wir jedoch an die eigenen Untersuch- 
ungen gehen, ist es merlässlich, eine kurze Darstellung des ausserhalb des thierischen Körpers verlanfenden Fäulnissprocesses zu geben.

Die Auflösung der organischen Substanz zu Ammoniak, Kohlensäure und Wasser vollzieht sich unter Erscheinungen, welche durch ihre Auffälligkeit vor Ignorirung geschützt waren. Trotzdem die Fäulniss das unentrinnbare Loos aller irdischen Grösse von je gewesen, gehört dennoch der Process zu den am wenigsten gekannten Naturerscheinungen. Wie das Endziel erreicht wird, ist in wesentlichen Dingen noch unbekannt, wir wissen nur jetzt, wodureh es erreicht wird. Die Fäulniss ist eine Arbeitsleistung der kleinsten organischen Wesen, der Bacterien, durch deren Abhaltung oder Tödtung daher auch die Fäulniss gehindert werden kann. So viel wissen wir, mehr jedoch nicht. Unsicher ist es schon, welche Ait von Bacterien es ist, die als eigentliches Fäulnissferment zu betrachten ist. Gesellschaftlich wie auch sonst wohnen in Fäulnissaufgüssen Monas crepusculum, Bacterium termo, Bacillus subtilis, also Kugel-, Stäbchenbacterien, auch Schraubenbacterien der verschiedensten Art nebeneinander. Ferdinand $\mathrm{Cohn}$ findet Bact. termo nicht nur an Zahl überwiegend und eine Zeit lang sich in der Regel ganz allein, fast ohne fremde Beimischung vermehrend, sondern er fasst auch diese Bacterienform als das eigentliche Fäulnissferment auf. Er sagt l. c. S. 169: „Bact. termo vermehrt sich in sehr kurzer Zeit in allen thierischen und pflanzlichen Aufguissen, Anfangs allein in unendlicher Zahl Schwärme bildend und verschwindend, sobald sich andere Arten vermehren, denen sie zur Nahrung dient; sie findet sich von Neuem im Uebermaass, sobald die Infusion zu stinkend wird, als dass andere Arten darin leben können. In unzählbaren Myriaden erfiillen sie das. Wasser, sobald in ihm Fäulnissstoffe vorhanden, mitunter so dicht, dass das Wasser zu einer lebendigen Gallerte wird; sie vermehren sich, so lange die Fäulniss fortschreitet, und schwinden, wenn sie voriber ist. In ähnlicher Weise, wie Hefe das Ferment der Alkoholgährung, ist meiner Ueberzeugung nach Bact. termo das Ferment der Fäulniss. Ich vermuthe sogar, dass die iubrigen Bacterien, obwohl sie zum Theil wenigstens bei dem Fauninissprocesse mitwirken, doch dabei nur eine secundäre begleitende Rolle ausiüben, während Bact. termo der primäre Erreger der Fäulniss, das eigentlich saprogene Ferment ist".

Pathologischerseits hingegen fand man in fauligen Wundsecreten kleine runde bewegungslose Zellen in Haufen dichtgedrängt aneinander liegend oder zu rosenkranzförmigen Fäden vereinigt, die Klebs bekamtlich als Microsporon septicum hingestellt hat, und 
Orth glaubt mit Entschiedenheit jede Betheiligung der länglichen stäbchenförmigen, mit lebhafter Eigenbewegung begabten ganz unschädlichen Fäulnissvibrionen an dem Zustandekommen der durch Sporen veranlassten septischen Processe zurtickweisen zu können. (Berliner klinische Wochenschrift 1872 Nro. 33). Nach Cohn hingegen erregen die Kugelbacterien, also auch Microsporon septicum, nicht Fäulniss, sondern Zersetzungen anderer Art, sie kämpfen in der Regel mit den Fäulnissbacterien auf dem nämlichen Boden um das Dasein und ihre Producte werden, wenn sie unterliegen, von den Fäulnissbacterien zerstört.

Es steht demnach so, dass Bacterium termo, welches jetzt als das alleinige Fàulnissferment ausserhalb des Körpers angesehen wird, bei den Fäulnissprocessen im Körper nicht angetroffen wird, in welchen im Gegentheil eine Spore, Microsporon septicum, in grösster Menge aufzufinden ist. Den versöhnenden Gedanken, ob die Sporen nicht blos juingere Entwickelungszustände von Bacterium termo sind, weist Cohn zurïck (1. e. S. 148), "weil die Zoogloeaform von Bacterium termo in der Regel durch die viel reichlicher entwickelte Intercellularsubstanz von den dichtgedrängten Schleimmassen der Kugelbacterien $\mathrm{zu}$ unterscheiden ist; auch ist die Intercellularsubstanz der letzteren in der Regel im Wasser leichter löslich". Klebs meint jedoch (Zeitschrift für experimentelle Pathologie I. Bd. S. 63), es sei noch eine offene Frage, ob das Bacterium termo faulender Flüssigkeiten seine besondere Form der Zusammensetzung der Nährflussigkeit verdankt; ,pathologisehe Thatsachen, insbesondere das Fortschreiten septischer Infectionsprocesse zu wirklicher Fäulniss machen indess die Zusammengehörigkeit zwischen Mierosporon septicum und Bact.termo wahrscheinlich; innerhalb der vielzelligen Familien (Zoogloea) der Micrococcen wachsen diese letzteren zu stabförmigen Gebilden (Bacterien) heran, die sich loslösen und frei beweglich werden."

Nicht klarer als die organische ist die chemische Seite des Fäulnissprocesses. Die Aufgabe ist weder durch Panum's putrides Gift, "noch durch Bergmann's und Schmiedeberg's schwefelsaures Sepsin gelöst, denn es handelt sich darum, die ganze Stufenleiter klarzulegen, in welcher sich die allmälige Umwandlung der Eiweissstoffe bis zu den Enàproducten vollzieht. Wohl wissen wir, dass dabei Schwefelverbindungen, wie Schwefelammonium und Sehwefelwasserstoff, Leucin, Tyrosin, organisehe Säuren, wie Buttersäure, Baldriansäure, Ameisensäure, und die verschiedensten Ammoniakverbindungen vorkommen, aber es fehlt uns die nothwendige Einsicht in die Entwickelung und Umwandlung der Stoffe. 
Endlich wissen wir noch ganz und gar nichts iiber die Art und Weise, wie die Bacterien ihre chemische Arbeit verrichten. Nach allen Richtungen der Windrose gehen die Eventualitäten anseinander, welche $\mathrm{Coh} n$ für möglich hält. „Sie zersetzen Eiweiss, indem sie es assimiliren, oder ein fliussiges Ferment ausscheiden, das Eiweiss löst oder chemisch verändert, oder indem sie Sauerstoff' den Albuminaten entziehen, oder grad umgekehrt activen Sauerstoff auf die Albuminate übertragen. Die Bacterien ernähren sich jedenfalls von den faulenden Eiweissstoffen und haben wahrscheinlich die Fähigkeit, die Eiweissmoleküle zu spalten in Ammoniak, das zunächst von ihnen assimilirt wird, und andere flüssige and gasförmige, zum Theil durch den Geruch charakterisirte Nebenproducte, die wohl auch dazu verwendet werden, unlösliche Verbindungen löslich zu machen, also Muskelfasern in Schleim aufzulösen."

Die nachfolgende Arbeit hatte es nicht mit dem Fäulnissprocess ausserhalb des Körpers zu thun, sondern nur mit seiner Wirkung auf den thierischen Organismus. Sie fand jedoch auf ihrem Wege Thatsachen, deren Ursachen so sicher ausserhalb gelegen waren, dass sie dahin verfolgt werden mussten. Unerlässlich war es dabei, mir fremde Gebiete, insbesondere in der Mykologie, zu betreten. Eine Dilettantenarbeit darin zu liefern, beabsichtige ich aber nicht, ich will nur beschreiben, was ich gesehen habe, an den Stellen, wo es' hingehört.

Die Stadièn des Fäulnissprocesses.

Die Frage nach der Identität und Constanz des Stoffes ist die erste, die uns bei jeder Untersuchung und nicht am wenigsten bei denen mit Fäulnissstoffen zu beschäftigen hat. Sind-doch hier schon die groben äusseren Veränderungen auffällig im Geruch, in der ganzen physkalischen Beschaffenheit, die allmälige chemische Umwandlung steht ausser aller Frage. Ist nun die Totalwirkung des Fäulnissprocesses auf den ganzen Körper, das Product aller einzelnen Factoren, ein nur quantitativ in sich verschiedenes, oder ist es ein qualitativ differentes? Setzen wir die Antwort sofort an die Spitze: Nach seinen Wirkungen auf den Organismus zerfällt der Fäulnissprocess in drei verschiedene Stadien: in ein phlogogenes, in welchem er nur Entzündungen zu erzeugen im Stande ist, in ein septogenes, in welchem er auch am lebenden Organismus seinerseits Fäulnissprocesse hervorrufen kann, endlich in ein pyrogenes, in dem er diese Fähigkeit wieder eingebüsst hat und nur noch Eiterungen zu erzeugen fähig ist. Diese drei Stadien sind von sehr verschiedener Dauer, 
nicht streng von einander abgeschlossen, sondern allmälig ineinander übergehend, auf ihrer Höhe aber von charakteristischer Beschaffenheit. Mit dem allmäligen Wechsel der Wirkung ist auch eine allmälige Metamorphose in der faulenden Fliissigkeit verbunden, eine physikalische wie mikroskopische; sie sollen nun gemeinsam geschildert werden.

Der Schilderung zu Grunde gelegt ist die Veränderung, welche die in Wasser faulende Muskelsubstanz erleidet, und die Wirkung, welche sie in der ganzen Zeit ihrer Fäulniss ausüibt. Faulende Muskelsubstanz ist nicht blos deshalb gewählt, weil ron diesem Object relativ wohl am häufigsten Gefahr droht, sondern deshalb vor Allem, weil es seiner Cohäsion wegen den Fäulnissprocess so retardirt, wie dies selten und bei blossen Flüssigkeiten nie der Fall sein wird. In derselben Absicht, der möglichen Verzögerung, um alle Metamorphosen zur Kenntniss zu bringen, ist die definitiv abschliessende Versuchsreihe im Winter angestellt. Es versteht sich, dass die so erlangten Zahlen lange Perioden, wenn auch vielleicht nicht die längsten, ergeben haben. Zum Zwecke grundlegender Studien sind aber diese unentbehrlich. Giebt Ferdinand $\mathrm{Cohn}$ an, dass bei seiner am 16. November 1871 angesetzten Nährflïssigkeit bereits am 9. December sich die Flüssigkeit klärte, während ein weisser flockiger Niederschlag von 1 C.-C. Höhe sich zu Boden schlug, so beweist dies nur, um wie viel rascher jede Flüssigkeit fault, deren Fäulniss durch physikalische-Bedingungen nicht aufgehalten wird. In meinen Fällen, in welchen ich in einem Porzellangefisse ron $46 \mathrm{Grm}$. $25 \mathrm{Grm}$. Fleisch in $20 \mathrm{Grm}$. Wasser faulen liess, so zwar, dass ich den durch Verdunstung und Entnahme von Probeflüssigkeiten entstandenen Gewichtsverlust immer wieder durch Zugiessen von Wasser deckte, danerte die Füulniss in der kithlen Jahreszeit länger wie 8 Monate an. Zur Erzielung vergleichbarer Resultate wurde regelmässig dieselbe Quantität Probeflüssigkeit, 1 C.-C., zur Anwendung gebracht, nie mehr. Denu bei unseren Versuchen handelte es sich nicht um Wiederholung der Fieberwirkungen, dies ist längst gethane Arbeit, anch überhaupt nicht um Massenwirkungen, sondern grad nmgekehrt um die Intoxications- und Bacterien-Proliferations-Frage, die nur durch kleine Dosen entschieden werden kann. Hin und wieder sah ich mich deshalb veranlasst, noch kleinere Dosen als 1 C.-C. in Anwendung zu bringen, was an den betreffenden Stellen besonders bervorzuheben sein wird. Vom 2. Tage der Fäulniss ab entnahm ich Proben, Anfangs täglich, später in längeren Zeiträumen; die mikroskopische Untersuchung 
ging mit der Anwendung bei Thieren Hand in Hand. Das Fleisch stammte von gesunden Thieren und wurde nicht klein zerschnitten; anch die Modification dieser Versuchsbedingungen wird ausdriicklich zu erwähnen sein. Eine absolute Gleichheit und Constanz aller Versuchsbedingungen zu erzielen, der Temperatur, des Wassers, der Beschaffenheit des Muskels selbst, ist kaum möglich, erscheint mir auch nicht wesentlich, eine annähernde gentigt. Denn die Erlangung relativer Werthe ist hier von grösserer Bedeutung, als die absoluter Zahlen.

In der ursprünglich ganz klaren Flüssigkeit sehen wir nach einigen Tagen ein oder mehrere zarte Häutchen sich bilden, während das Fleisch selbst unverändert erscheint. Allmälig geht der rothe Farbestoff des Fleisches in das Wasser über, welches immer dichteren Ueberzug bekommt, auf dem sich hin und wieder noch Schimmel bildet. Die Flüssigkeit, die im Winter in den ersten Tagen gar nicht riecht und erst später den gewöhnlichen faulen Fleischgeruch darbietet, zeigt bei der mikroskopischen Untersuchung meist bereits vom zweiten Tage ab eine Zahl grosser und kleiner in lebhafter Theilung begriffener Bacterien. Wenn auch neben ihnen kleinere Sporen anzutreffen sind, so bleibt doch das charakteristische Bild dieses Stadiums das bewegliche muntere Spiel der Bacterien (Bacterium termo) in sehr wechselnder Grösse. Wiewohl deren Zahl in sehr starker Zunahme continuirlich begriffen ist, kann das phlogogene Stadium im Winter bis zum 7. Tage andauern, d. h. die Fliissigkeit ist trotz der Nachweisbarkeit von Bacterien nicht im Stande ihrerseits einen septischen Process am lebenden Körper auszulösen, sondern sie bringt nur eine acute Entzuindung hervor und zwar, wie hervorzuheben wichtig ist, eine blosse Resolutionsentzündung, eine solche demnach, welche nach einigen Tagen verschwindet, ohne irgend welche locale Folgen zu hinterlassen. Wir sehen also, dass hier nachweisbar der Jebergang von Fäulniss-Bucterien erfolgt ist, unter gewöhnlichen, ja unter ganz leichten. Entzündungserscheinungen, ohne dass eine locale massenhafte Proliferation der Bacterien stattgefunden hätte. Dies Resultat ist von principiell entscheidender Wichtigkeit. Die Entziindung wird bei den Krankheitsformen näher zu schildern sein.

Hier jedoch schon muss constatirt werden, dass bei Muskeln, welche von an Sepsis gefallenen Thieren stammen, das phlogogene Stadium ganz ausbleiben kann, dass das mit solchem Muskel angesetzte Wasser oft sogleich septische Wirkung ausübt, nachdem es einige Stunden mit dem Muskel in Berührung gewesen. 
Zu Ende der ersten Woche pflegt überall das phlogogene Stadium der Sepsis allmälig in das septogene überzugehen. Unter septogenem Stadium verstehen wir dasjenige, in welchem die Flüssigkeit die Fähigkeit hat, septisch zu wirken. Die Fähigkeit der septischen Wirkung schliesst nicht die Nolhwendigkeit derselben in sich. Noch mehr wie bei andern schädlichen Potenzen hängt es von den Umständen $a b$, ob die potentielle Fähigkeit zu einer actuellen wird. Kann die eingeführte septische Flüssigkeit sich in den Gewebsinterstitien leicht vertheilen, über eine grössere Region sich ausbreiten, so wirkt sie weniger intensiv auf jede einzelne Stelle, als wenn ein straffes, Widerstand leistendes Gewebe diese Ausbreitung hemmt. Trifft dieselbe Flüssigkeit auf ein sehr reichliches Gefässnetz, auf mehrere übereinander geschichtete Gefässlagen, so wird in derselben Zeiteinheit durch Resorption eine grössere Menge Flüssigkeit in das Blut iibergeführt und daher local unschädlich gemacht werden, als wo die Vascularisation eine geringe ist. In beiden Fällen nimmt die Intensität der Wirkung nur auf Kosten ihrer Extensität ab, der locale Effect ist aber immer geringer. Dass im Kaninchenohre beide Momente zu Ungunsten der Localwirkung ausfallen, dass das Gewebe straff, die Vascularisation schwach ist, erklärt die bei diesem Organe überraschende, aber zweifellos zu constatirende Neigung zur Sepsis. Während das Kaninchenohr offenbar wegen seiner Säftearmuth in gewöhnlichen Fällen nach dem Tode weniger der Fäulniss unterliegt, als irgend eine andere Körperstelle dieses Thieres, lässt sich bei subcutaner Injection septischer Flüssigkeiten nirgends frther und an keiner stelle länger Sepsis erzeugen, als hier. Zu Zeiten, wo man mit derselben Menge derselben Flüssigkeit in der Musculatur Eiterung, an anderen Hautpartien progressive Jauchung erzielt, erhäIt man am Ohre bereits septische Gangrän; daher sind die Ohrversuche das feinste Reagens zur Constatirung der Sepsis iiberbaupt, zur Feststellung ihrer Zu- und Abnahme, eben deshalb aber natürlich nicht schlechthin musterguiltig. Rechnet man das ganze septogene Stadium so lange, als zweifellos septische Processe am Ohre noch erzeugt werden können, so dauert es in toto im Winter über drei, vier Monate hinaus.

Was haben wir als specifisch septische Processe anzusehen? Solche, welche in gar keiner anderen Krankheit vorkommen, sondern nur für die ausgeprägte Sepsis charakteristisch sind. Die mit blaugrüner Verfärbung des Parenchyms und mit starkem Fäulnissgeruch verbundene Blutgerinnung am lebenden Thiere ergiebt in der septischen Gangrän ein so eigenthümliches Krankheitsbild, dass 
dasselbe als ein durchaus specifisches angesehen. werden muss. In diesem Falle iibt die Sepsis gleiche Wirkung auf Leben wie auf Tod. Dies ist also der feste Punkt, von dem wir auszugehen haben, mit diesem Maassstab mï̈ssen wir messen. Diesen Maassstab der septischen Gangrän des Ohres für das ganze septogene Stadium festhaltend, sehen wir, dass im Anfange dieses Stadiums an anderen Stellen nur Entziùdungen zu Stande kommen, dass auf seiner Höhe uiberall Sepsis eintritt und dass nach iiberschrittener Höbe nur Eiterungen an den meisten Stellen zu erzielen sind. Es ist also eine continuirliche Kette vorhanden, welche das septogene Stadium mit dem vorangegangenen phlogogenen und dem nachfolgenden pyogenen verbindet. Da sich das ganze septogene Stadium über mehrere Monate erstreckt, so könnte man als Unterabtheilungen desselben ein $p$ hlogo-septogenes, ein rein septogenes Stadium und ein septo-pyogenes statuiren. Im Laufe des ganzen Zeitraumes treten auch sichtbare Veränderungen der Fäulnisssubstanz auf. Der rothe Farbstoff ist nicht nur allmälig aus dem Fleische ausgewaschen, er ist auch wieder in der Flïssigkeit zerstört worden, die Auflösung der Fasern selbst hat Fortschritte gemacht, so dass mehr und mehr die Flüssigkeit mit der Substanz einen Brei bildet, Anfangs ungleichmässig, später dicklich homogen, allmälig auch an Consistenz abnehmend, so dass man schliesslich eine graugefärbte Flüssigkeit vor sich hat. Auch der Geruch wechselt bei demselben Stoffe. Der gewöhnliche faule Fleischgeruch ist nach 3 Wochen einem unvergleichlich stänkrigen gewichen, um im Höhestadium der Fäulnisswirkung wieder einem käsigen Platz zu machen, der zu Ende dieser ganzen Periode in einen erdigen ibergeht. Das Wichtigste bleibt: auch die mikroskopischen Bilder ändern sich in allmäligem Wechsel. An Stelle der mobilen, in lebhafter Theilung begriffenen Bacterien (von Bacterium termo) treten nach 8-14 Tagen zahlreiche rosenkranzförmige Sporenketten auf, die jetzt neben der Sporenmenge iberhaupt mehr in den Vordergrund treten, als die Bacterien von geringerer Grösse und Beweglichkeit erscheinen. Auch die Sporenketten schwinden wieder und nach $4-6$ Wochen bietet die Flüssigkeit ein ganz neves 13ild dar. Hatten wir bisher mit Stäbchenund Kugel-Bacterien zu thun, so treffen wir jetzt Fadenbacterien an, gerade Fädchen (Bacillusform), wellig gelockte (Vibrioform). Länger und im Verhältniss schmäler als die Stäbchenbacterien erfüllen sie in ungeheuren Mengen die Flüssigkeit und fesseln den Beschauer nicht blos durch die Lebendigkeit, sondern anch durch die scheinbare Selbstständigkeit ihrer Bewegungen. Dieses hübsche Bild ist 
auch von älteren Beobachtern oft gesehen worden und jedem drängt sich das Gleichniss auf, dass muntere Fischchen dicht besäet einen Teich erfitllen und unter- mit- und gegeneinander schwimnen, von frohester Lebenslust beseelt. Hier liegt der Gedanke, dass man es nicht mit willenlosen, sondern mit willkürlichen Bewegungen kleiner Thierchen zu thun hat, am allernächsten. Der Höhepunkt dieser Entwickelung fällt oft mit der Höhe des ganzen septogenen Stadiums zusammen, doch nicht ausschliesslich. Auch dieses Bild ist nicht von Dauer, und macht dem einer gleichmässigen sämigen Sporen- und Detritusmasse Platz. Es ist die Zeit voller physikalischer Auflösung der Masse, selbst die letzten Reste quergestreifter Muskelfasern sind aus dem Bilde geschwunden. Wir sind damit an das Ende des ganzen septogenen Stadiums gelangt, d. h. auch im Winter zu Ende des 4. bis 5. Monats. Schon hier ist es einer besonderen Hervorhebung werth, dass in das specifisch-septogene Stadium hinein auch der Höhepunkt der Allgemeinwirkung, der Septicämie fällt. Ja es giebt einen kurzen, nicht immer leicht abzupassenden Zeitraum, den man geradezu als den der Septicaemia fulminans betrachten könnte, in welchem die Flüssigkeit von so intensiver, man kann kaum anders sagen, giftiger Wirkung ist, dass ein Tropfen auf eine offene Wundstelle gebracht, den Tod in einigen Stunden zur Folge hat, ohne dass es überhaupt zu ausgeprägten Localerscheinungen kommen kann, so rasch tritt der Tod ein. Diese Septicaemia fulminans ohne nachweisbare Localaffectionen erinnert an Virchow's ursprüngliche Definition der Ichorrhämie, als einer Krankheit, wo die Erscheinungen der allgemeinen Störung so frühzeitig auftreten, dass weder Eiter noch faulige Umwandlungen rorausgegangen sein können, ja in manchen Fällen findet sich überhaupt nirgends im Körper weder Eiter, noch Brand, noch Fäulniss. Da hier der septische Ursprung zweifellos ist, so ziehen wir den Ausdruck Septicaemia fulminans in diesem Falle vor, auch duirfte die fernere Forschung auf diesem weiten Gebiete der Ichorrhämie einen concreten von der Sepsis unabhängigen Inhalt zuweisen. Die Septicämia fulminans tällt, wenn man die Wirkung graphisch auftragen will, nicht in die Mitte der ganzen septischen Periode, sondern in eine frïhere Zeit, da die septische Wirkung rasch zum Maximum ansteigt, um zwar nicht auf der Maximalhöhe, aber etwas unter derselben längere Zeit unter sehr allmäliger Abnahme zu verbleiben.

Vom septogenen Stadium, genauer von dem septo-pyogenen, erfolgt nun der allmälige Uebergang zum rein pyogenen Stadium, in welchem 
nur Eiterungen zu erzielen sind. Mit kleinen Dosen von 1/2 C.-C. erhält man dieselben natiurlich leichter als bei 1 C.-C., wo noch leicht septische Modificationen eintreten, bestehend in schwacher Grundfärbuug, unbedentendem Geruch, aber ohne eigentliche septische Gangrän. Allmälig schwinden auch diese Spuren. In der grauen Flüssigkeit lassen sich jetzt wieder neben ruhenden Sporen glänzende bewegliche Bacterien erkennen, die man wohl zu den Stäbchenbacterien am ehesten rechnen kann, die aber wieder ganz anderer Art sind als Bacterium termo. Sie sind grösser, breiter, auch glänzender als jene, in viel geringerer Zahl, treten immer einzeln ihre Promenade an, bald schwirrend und sich um sich selbst drehend, bald geradewegs und ziemlich rasch das ganze Gesichtsfeld durchlaufend, and haben keine Aehnlichkeit mit den Arten, die ich bisher bei anderen Stadien beobachtet habe.

Die progressiven Processe, welche durch Vermehrung der Bacterien im Körper entstehen, kommen sowohl im ganzen septogenen als auch im pyogenen Stadium vor, sind also für die Abgrenzung der Stadien nicht zu verwerthen.

Durch die allmälige Umwandlung derselben Substanz sehen wir also Hand in Hand mit der inneren Metamorphose eine ganz verschiedenartige Wirkung einhergehen. Trotz steter Anwesenheit von Bacterien sind in gewissen Zeiträumen nur Eiterungen, ja nur blosse Resolutionsentzündungen zu erzielen, in anderen wieder treffen wir auf Giftwirkungen, die den Vergleich mit den schlimmsten Giften auch in Betreff der Acuität ihres Eintretens nicht zu scheuen haben. Ein Wandel, wie er grösser nicht gedacht werden kann. Dabei hatten wir es hier nur mit einem einzigen Gewebe zu thun und mit dessen Veränderungen unter den einfachsten Verhältnissen. Wie ausserordentlich mannigfaltig trotz äusseren Aehnlichkeiten wird sich der gleiche Reductionsprocess zu Ammoniak, Kohlensäure, Wasser, bei den so verschiedenartigen organischen Ștoffen, gestalten, und wie viele Krankheitsursachen mögen in ihnen schlummern.

Es bleibt unsere nächste Aufgabe, die Krankheitsformen kurz zu schildern, welche durch die verschiedenen Stadien des Fäulnissprocesses erzengt werden können. Die Schilderung kann kurz sein, denn nicht um Aufstellung neuer Krankheitsbilder handelt es sich zumeist, sondern um ihre Einordnung an richtiger Stelle.

Die Krankheitsformen:

a) im phlogogenen Stadium.

Dass bereits am zweiten, dritten Tage nach der Anstellung des Muskels in Wasser Bacterium termo sich in der Flüssigkeit in er- 
heblicher Menge findet, lehrt ein Blick ins Mikroskop. Injicirt man 1 C.-C. solcher Flïssigkeit subcutan in das Kaninchenohr, so bemerkt man unmittelbar nichts Anderes, als dass die Flüssigkeit in der durch sie aufgeblasenen Ohrpartie feststeht, vorausgesetzt, dass man der Neigung zum Regurgitiren durch Compression mit dem Finger vorbeugt, und dass die Flüssigkeit etwa nur wie bei all diesen subcutanen Ohrinjectionen die Neigung hat, an der schwächsten Stelle dem lockeren Zellgewebe der Arteria auricularis entlang nach unten zu verlaufen. Die Ohrpartie zeigt die etwas röthliche Färbung der injicirten Flüssigkeit, aber weder local noch allgemein die geringste Ohrhyperämie. Am folgenden Tage bereits zeigt sich daselbst eine kräftige Entzïndung mit starker gleichmässiger Hyperämie, Schwellung und Hitze, die aber nur wenig über den ursprünglichen Locus affectionis hinausreicht und zur Progression keine Tendenz zeigt. Bis zu drei Tagen vom Ursprung an gerechnet, pflegt die Entzündung zuzunehmen, resp. sich auf gleicher Höhe zu erhalten, um sodann in Resolution ïberzugehen. Die Entzündung ist mit einem lebhaften Fieber verbunden. Sie löst sich allmälig vollständig, so dass das durchsichtige Ohrparenchym eine Woche später kaum eine Spur der überstandenen Entzündung und schliesslich gar keine Anomalie zeigt, noch anderweitig erkrankt. Wir haben also hier eine reine Resolutionsentzündung vor uns, genau so, wie sie von mir nach Injection dïnner Salzlösungen oder Farbstoffpartikeln beobachtet worden ist. ( $\mathrm{Samuel}$, die Genesis der acuten und chronischen Entziindung, Virchow's Archiv Bd. 55.) Es tritt keine Eiterung ein, keine Eiterung in dem gewöhnlichen Sinne des Wortes für mikroskopische Eiterungen gebraucht. Nur dann bildet sich ein sichtbarer Eiterpunkt, wenn man mit einer Nadel den Entzündungsherd durchsticht, und auch dann nur an der Stichstelle, ein Fall, auf den ich ein andermal bei Behandlung der Eiterungen zurïckkommen werde. Es macht, was beim Ohre mit aller nur wünschenswerthen Klarheit zu übersehen ist, keinen Unterschied, ob einzelne Venen verletzt, das eine oder andere kleinere oder selbst grössere Blatgefäss angeschnitten oder durch einen Thrombus geschlossen ist. Für den weiteren Vorgang sind derartige kleine Verletzungen ganz einflusslos. Ebenso gleichgillig ist es, ob neue oder ältere kleine Blutextravasate sich an der verletzten Stelle befinden, sie theilen das Schicksal der Stelle, beeinflussen es aber nicht.

Das Gesammtresultat der Resolutionsentzündung setzt sich zusammen aus der Resorption, der Entzündung und der Resolution. Dass die Resorption direct stattgefunden, beweist einerseits das 
rasche Verschwinden aus dem Gewebe, andererseits die eingetretene entzündliche Veränderung der Blutgefässe. Die Resorption der Bacterien hat nach dem Nachweis der Resorption der viel grösseren Farbstoffpartikel nichts Auffallendes. Die Entzündungsursache kann in den chemischen oder organischen Qualitäten der Flüssigkeit begründet sein, die Discussion hierüber wird erfolgreicher zu Ende der Abhandlung nach Bereitstellung alles zugehörigen Materials geführt werden können. Hier bereits lässt sich hingegen das wichtige Resultat feststellen, dass die Bacterien in kurzer Zeit örtlich sowohl aus dem Parenchym als aus den Blutgefüssen verschwunden sind, ohne dass es ersichtlich zu einer Wucherung derselben gekommen ist. Ausser dem kurzen Fieber lässt sich andererseits auch keine Spur eines Allgemeinleidens verfolgen, welches in diesem Versuche von den Bacterien hervorgerufen sein könnte; dieselben müssen also ausgeschieden oder wirkungslos geworden sein.

Damit ist schon bewiesen, dass nicht allen Bacterien, und hier speciell Bacterium termo nicht, unter allen Umständen jene perniciöse Wirkung auf den lebenden Organismus zukommt, die gerade dieser Art auf die todte organische Substanz eigen ist. Dieser Versuch aus dem Anfangsstadium der Sepsis beweist, dass septische Einflïsse ohne alle septische Folgen verlaufen können.

Höchstens jedoch bis zum Schlusse der ersten Woche sind diese geringfügigen Wirkungen zu erzielen. Dies ist der längste Termin selbst bei andauernder Kälte. Zwischen dem zweiten und dritten oder einem späteren Tage ist, so lange dieses Stadium überhaupt noch dauert, trotz der späterhin viel grösseren Zahl von Bacterien, in der Wirkung kein Unterschied.

b) im septogenen Stadium.

Die septische Gangrän. (Gangraena septica.)

Diese höchst charakteristische Affection stellen wir an die Spitze aller diesem Stadium eigenthümlichen Krankheitsbilder. In seiner vollen Ausprägung tritt es natürlich zeitlich sehr viel später auf, als die eben beschriebene leichte Entzündung, indess sind die allmäligen Uebergänge leicht zu constatiren. Heftigere Entzuindungen von längerer Dauer mit partiellem Ausgang in Blutgerinnung: und geringerem oder stärkerem Geruch werden allmälig von andern abgelöst, die noch lebhaftere Exsudation und umfangreichere Blutgerinnung mit sich führen, bis es schliesslich zu den ausgeprägtesten Formen kommt, bei denen vor der Gangrän keine oder unbedeutende Ausschwitzangen zu bemerken sind. Sehr fribzeitig und prompt tritt die Gangrän im Ohre bei Application von Flüssigkeiten aus 
diesem Fäulnissstadium nach Unterbindung der Carotis ein und da gerade diese Bilder sich durch besondere Klarheit auszeichnen, so wollen wir sie der nachfolgenden Schilderung zu Grunde legen. Unmittelbar nach der Injection sieht man die grünliche Flüssigkeit in der emporgewölbten Ohrpartie stehen, ohne dass locale oder allgemeine Ohrhyperämie einträte. Am folgenden Tage zeigt sich das Blut noch flüssig, das ganze Parenchym kanm verfärbt. Erst nach zweimal 24 Stunden ist in den Blutgefässen der afficirten Stelle Stase des Blutes zu beobachten, dariiber hinaus in dem ganzen Blutgefässnetz geringere Flïssigkeit and Beweglichkeit des Blutes, fortschreitend bis zum Stillstand. Es ist bemerkenswerth, dass zu einer Zeit, wo noch keine complete Stase zu beobachten ist und weder Blutaustritt noch grünliche Verfärbung des in den Blutgefässen circulirenden resp. stagnirenden Blutes bemerkt werden kann, im Parenchym bereits eine gleichmässige blaugrüne Verfärbung sichtbar ist, weshalb diese letztere als eine coordinirte directe Wirkung der Fäulnissfluissigkeit auf das Gewebe zu betrachten sein wird. In den nächsten Tagen bildet sich die Stase immer vollständiger zu einer completen Blutgerinnung unter Herstellung lockerer feuchter grünlich gefärbter Gerinnsel aus; das blaugrüne Ohrgewebe wird welk, verliert seine Elasticität und seine Wölbung. In dieser ganzen Zeit strömt das Ohr einen intensiven Fänlnissgeruch aus. Auch dieser Zustand geht nach weiteren 48 Stunden voriber und macht einer ausgesprochenen gangränösen Schrumpfung Platz, bei der das Blut zu einer schwarzen festen resistenten Masse vertrocknet, das ganze Ohr zu einem kurzen sehwarz aussehenden Stumpfe zusammenschrumpft, durch dessen Ausbreitung man kaum die ursprünglichen Contouren des Ohres wieder herzustellen im Stande ist. Von grösster Wichtigkeit ist es nun, dass diese Gangrän sich selbst begrenzt durch eine sichtbare Demarcationsentziundung, welche eine Eiterlinie an der Grenze producirt, durch die die Abstossung erfolgt. Die Demarcationsentzündung kommt nach Unterbindung der Arterie langsamer zu Stande und mehr central als ohne dieselbe, aber sie tritt, kommt der Tod nicht dazwischen, in beiden Fällen ein.

Eine ganz gleich verlaufende septische Gangrän lässt sich am Unterschenkel nach Unterbindung der Arteria femoralis ebenfails durch Injection kleiner Mengen septogener Flüssigkeit erzielen. Wird hier sofort nach der Unterbindung die Injection in die Gegend der Achillessehne gemacht, so zeigt sich am folgenden Tage starke Schwellung des Beines bei ausgesprochener Kälte desselben. Schon nach zweimal 24 Stunden lösen sich Hant und Haare an verschie- 
denen Stellen ab, das Bein bricht auf, oft aber früher an dem Malleolus als am Fusse selbst. Der Fäulnissgestank ist penetrant. In den blossliegenden, durch spontane Ablösung der Umgebung freipräparirten Blutgefässen ist das Blut in ein lockeres grünliches Gerinnsel verwandelt, wie der äussere Anblick und die Anfschlitzung der Gefässe beweist. Auch hier wieder geht dieser Zustand innerhalb 24-48 Stunden voriber, um der ausgesprochenen Mumification Platz zu machen, bei der die volle Vertrocknung des Fusses bis zur Mitte der Wade hinaufreichen kann, die Partie schwarz wie verkohlt aussieht und das Blut ganz trocken bröckelnd wird, kurz ein Brand, dem man seinen Fäulnissursprung in diesem Stadium nicht mehr ansieht, und der denseiben jetzt weder durch sein Aussehen, noch durch seinen Geruch verräth. Auch hier bildet sich eine Demarcationsentzündung, welche in glücklichen Fällen mit der Selbstamputation des Fusses unter voller Reconvalescenz des Thieres heilt.

Diese beiden Fälle haben wir vorangestellt, weil sie durch klaren ungetrübten Verlauf sich auszeichnen und so das treueste Bild der Gangraena septica gewähren. Ist die Carotis nicht unterbunden, so kommt es, wie fruiher bereits ausgefïhrt, in diesem septogenen Stadium ebenfalls im Ohre zar Gangrän, selten aber, ohne dass zuvor Anläufe zur Exsudation stattgefunden hätten. Anläufe, die dis Gesainmtresultat durchaus nicht ändern, das Krankheitsbild aber trüben. Von dieser Exsudation als einem unwesentlichen Vorgange können wir zunächst bei der Discussion der septischen Gangrän ganz absehen. Was wir vor uns haben, ist Blutgerinnung und Brand, ganz ähnlich dem durch andere chemische Stoffe hervorgebrachten Brande und allein durch dev eigenthümlichen Fäulnissgeruch und die Färbung besonders charakterisirt. Ist nun diese Wirkung ein Product der mechanischen und organischeu Potenzen der neuen in diesem Stadium zur Geltung gelangenden Bacterien, oder ist dieselbe eine Folge der in den Bacterien resp. in der Flüssigkeit wirksamen chemischen Stoffe? Mittelst ibrer organischen Potenz als wachsthums- und theilungsfähige Körper könnten sie von aussen her durch Compression, von innen her durch Obturation den Kreislauf in den Blutgefässen unterdriucken. Um von aussen her durch Compression Brand, d. h. eine volle Unterdrückung des Blutkreislaufs z erzielen, miisste die Proliferation der Bacterien in wenigen Tagen eine nicht blos sehr rasche, sondern enorm umfangreiche gewesen sein. Es wird weiterhin bei den progressiven Processen der Nachweis geführt werden, dass die Proliferation nicht so rasch eintritt, 
dass die umfangreichste aber selbst nie die mechanische Gewalt ausiibt, um den Kreislauf in den Arterien zu unterdruicken. Ebensowenig kann hier von Verstopfung der Blutgefässe durch Bacterien die Rede sein. In die Blutgefässe eingedrungen, würden sie und ihre Nachkommen immer wieder von dem Blutstrom fortgeschwemmt und in den Körperkreislauf geworfen werden, und könnte es hie und da auch zu kleinen Gefässverstopfungen kommen, doch nimmer zu solchen, welche einen bestimmten Abschnitt ganz unwegsam machen, in den Venen jenseits desselben die Circulation aber ganz intact lassen. In beiden Fällen mïsste eine complete Anämie der Gangrän vorausgehen; aber auch von dieser ist, von den Fällen abgesehen, in denen die Arterie unterbunden worden, keine Spur nachweisbar. So bliebe denn, sieht man von diesen mechanischen Momenten ab, nur noch eine Hypothese uibrig, welche an die organische Potenz der Bacterien anknipft, die Absorptionshypothese, d. h. diejenige, welche in der durch die Bacterien stattfindenden Absorption ron Nährtlüssigkeiten das patholog. Moment sieht. Auch der Gedanke, dass bei continuirlichem Blutstrom die Ernährung einer sehr grossen Anzahl ron Bacterien zu einer solchen Austrocknung des Blutes fuibren könne, dass dadurch locale Gangrän herbeigeführt wird, braucht nur formulirt zu werden, um in seiner Abentenerlichkeit erkannt zu werden. Als Causa proxima der septischen Gangrän können wir daher nur die chemischen Potenzen der Bacterien anerkennen, wie bei Beurtheilung des Wesens der Sepsis zum Schlusse der Arbeit auseinandergesetzt werden soll.

Es sind noch einige Punkte bei der septischen Gangrän, welche eine nähere Beriicksichtigung verdienen, zunächst das grïnfeuchte Blutgerinnsel, in welches das Blut dieser Stelle sich umgewandelt. Wo wir frïher bei anderen Brand- und Entzuindungsformen auf Gerinnsel in den Blutgefässen stiessen, waren es fast ausnahmslos solche, die wegen ihrer eigenen Trockenheit, wie wegen ihres festen Hängens an der Gefässwand zur Circulation wie zur Wirkwng wenig: tauglich erschienen. Hier haben wir aber mindestens 24-48 Stun den hindurch feuchte Gerinnsel vor uns von leichterer Ablösbarkeit von der Gefässwand. Kein Zweifel, werden Flockchen oder grössere Brocken eines solchen Gerinnsels in den Blutstrom geschleudert, so miissen sie in den Lungen nicht blos stecken bleiben, sondern wegen ihres septischen Inhalts auch einen perniciösen Einfluss ausiiben, die Metastase derselben miisste von metastatischen Abscessen gefolgt sein. Alle zu dieser Kette nothwendigen Glieder sind vorhanden, und dennoch sehliesst sich die Kette nicht, d. h. metasta 
tische Abscesse sind trotz alledem nicht nachweisbar, weil hier bei der Gangrän die Demarcationsentziündung das Gerinnsel fruhzeitig rom Gesammtkreislauf abschliesst. Dureh diese Intervention wird sichtlich ein pathologischer Process hintangehalten, dessen Eintreten mit Sicherheit zu erwarten war, eine beredte Warnung, wie mir scheint, in der Pathologie nicht so leicht Möglichkeiten für Wirklichkeiten zu halten und die hindernden Umstände zwischen ihnen zu uibersehen.

Die Demarcationsentzuindung, die am untern Drittel des Ohres eintritt, wenn wie bei allen diesen Versuchen die Injection zu Anfang des zweiten Drittels in der Nähe der Art. auric. gemacht ist, bietet besondere Erscheinungen nicht dar. Auch ihr Eintritt erfolgt langsamer zwar, aber sicherer nach Arterienunterbindung, als ohne dieselbe, besonders wenn im letzteren Falle noch die Injection ein wenig tiefer vorgenommen worden, so dass ein Theil der septischen Fliussigkeit bis zum Nacken dringen konnte. Der durch die Allgemeininfection bedingte Tod verhindert dann leicht die Ausprägung der Localerscheinungen. Denn um es hier gleich zu sagen; nur an den extremsten Körperpartien tritt die septische Gangrän so scharf und doch so isolirt auf, wie wir eben beschrieben haben, also am Ohre, an den Enden der Extremitäten und unter ähnlichen anatomischen Verhältnissen, die einen relativ geringen Zusammenhang durch Parenchym und Gefässe mit einander gemein haben. Wo in median gelegenen Theilen eine Ausbreitung der septischen Flüssigkeit nach verschiedenen Seiten möglich ist, da wird, wie schon bemerkt, die Intensität der localen Wirkung geringer, die Extensität derselben durch Progression im Parenchym grösser werden und durch das rasch auftretende Algemeinleiden gleichzeitig eine andere Reihe von Erscheinungen hervorgerufen werden. Diese Betrachtung füihrt zunächst zur Darstellung der progressiven Processe.

Die Progression septischer Processe (die progressive Jauchung, das Erysipelas malignum, das Erysipelas simplexc).

Unter der Bezeichnung progressive septische Processe fassen wir eine Anzahl von Krankheiten zusammen, deren gemeinsamer Ursprung aus Fäulnissbacterien nachweisbar ist, ein Ursprung, dem sie auch sämmtlich den progressiven Charakter verdanken, der durch die Proliferation und Migration der Bacterien bedingt ist. Zweifellos gehören auch die Osteomyelitis ichorosa, Parametritis, die Peritonitis puerperalis und andere analoge progressive Erkrankungen septischen Ursprunges hierher, deren besondere Form nur durch die Eigenthümlichkeiten der Gewebe und Organe bedingt ist, 
in denen sie auftreten. Es ist eine ganze Krankheitsgattung, um die es sich handelt, mit gemeinsamen Charakteren bei grossen anatomischen und geringen ätiologischen Differenzen. Gehen wir von der progressiven Jauchung aus. Spritzt man septische Flüssigkeit 1 C.C. im phlogo-septogenen oder septo-pyogenen Stadium in lockeres Gewebe, in welchem eine weitere Verbreitung derselben leicht möglich ist, wie in das subcutane Gewebe des Oberschenkels, des Bauches, des Rumpfes, sō entsteht eine Janchung; welche die Neigung hat, sich weit über den ursprünglichen Locus affectionis auszudehnen, und weniger in die Tiefe als der Fläche entlang nenes Gewebe in ihr Bereich zu ziehen. Die Erscheinungen sind bekannt, ödematöse, auch wohl emphysematöse Schwellung der Gewebe, mit anomaler Färbung der Haut, welche ein dunkelrothes, violettes, auch grünliches Colorit annimmt. Von Pus bonum et laudabile keine Spur, hingegen überall ein wässeriges dünnflüssiges Secret, welches die ganze Partie durchtränkt, mehr oder weniger übelriechend ist und eine Menge von Sporen, aber wenig ausgebildetere Bacterienformen enthält. $\mathrm{Zu}$ vollem Blutstillstand kommt es nur spät und an wenigen Stellen, ebenso auch nur selten zu brandiger Exfoliation einzelner Hautpartien. Hingegen ist ein rapid auftretendes Allgemeinleiden damit verbunden mit heftigem Fieber, das aber schliesslich einem ausgeprägten adynamischen Zustande Platz macht und mit Tod endigt, ein Zustand, der auf der Höhe des septogenen Stadiums sich sogleich obne alle Localleiden ausprägen kann.

Vergleichen wir hiermit das Erysipelas malignum. Macht man beim Kaninchen einen kräftigen Schnitt in die Haut des Nackens an der Basis beider Ohren, und bestreicht dann diese Nackenwunde mit mehreren Tropfen Flüssigkeit aus der phlogo-septogenen Periode, so verklebt die. Wunde, wenn sie klein war, in der Regel vollständig, ohne dass in den nächsten Tagen irgend eine bemerkenswerthe Veränderung an ihr auftritt. Die Stelle scheint ohne alle weitere Folgen zu verschorfen. Da bemerkt man am dritten, vierten Tage, selten später, noch seltener fruiher, dass an der Basis des einen, bald auch des andern, mitunter gleichzeitig beider Ohren eine Röthe vorhanden ist, herriihrend wie sichtbar von einer diffusen entziundlichen Hyperämie, verbunden mit geringfiigiger Schwellung. Rapid, in 3 bis 4 Tagen steigt diese Entziindung von der Ohrwurzel bis zur Ohrspitze hinauf. Diesen äusseren Verlauf theilt das Erysipelas malignum mit dem nachher zu schildernden Erysipelas simplex, doch im Weiteren trennen sich ihre Wege. Ehe noch die Gefässinjection die Spitze erreicht, ist beim Erysipelas malignum sehr deutlich mit 
blossem Auge das schon oft von mir beschriebene Phänomen der itio in partes in den oberen Blutgefässen zu erblicken, in so stark ausgeprägtem Grade, wie es nicht der Entzündung, sondern der Thrombose voranzugehen pflegt. Bei Fingercompression der Gefässe merkt man auch, dass das Blut sehr langsam seinen alten Platz einnimmt und nach wenigen Tagen ist es zweifellos, dass eine complete Blutgerinnung im Ohre eintritt. Das Ohr wird schwach blaugrün gefärbt, die Blutgerinnung ist so vollständig, dass das volle Absterben des Theiles unvermeidlich wäre, wenn nicht der Tod den weiteren Localverlauf unterbrechen wïrde. Intensiver Geruch ist dabei nicht wahrzunehmen, wie iiberhaupt von der Progression abgesehen der Vorgang mehr Aehnlichkeit mit der allgemeinen Thrombose besitzt, wie sie unter gewissen Umständen an Stelle der Entzündung, unter andern z. B. bei subcutaner Anwendung von kohlensaurem Ammoniak, im Ohre als Einleitung der Gangrän auftritt. Von der septischen Gangrän ist dieses Bild des Erysipelas malignum wesentlich verschieden, da bei jener alle septischen Phänomene in Aussehen, Geruch, in der ganzen Intensität des Auftretens stärker entwickelt sind. Das ist auch ganz verständlich, da es sich beim Erysipel nur va einen durch Bacterien forgeleiteten Process handelt, bej der Gangrän um einen Localprocess, der mit seiner vollen Wucht die occupirte Stelle getroffen hat.

Gleichzeitig mit der Fortleitung des Krankheitsprocesses vom Nacken zum Ohre sind correspondirende Krankheitsphänomene auch an andern benachbarten Körperstellen nachweisbar. Auf der Schleimhaut der Augen wie der Nase pflegen bald einseitig, häufiger beiderseits Katarrhe aufzutreten, welche mit starker Śchleimsecretion verbunden sind. $\mathrm{Zu}$ intensiveren Processen auf der Cornea etc. pflegt es nicht zu kommen. Diese Phänomene verschlimmern noch das eigenthümliche Aussehen, das die Thiere in diesen Fällen darbieten. Mit verklebten geschlossenen Augen und rasselnder Respiration sitzen sie wie unbeweglich mit ihren jetzt nicht mehr aufrechtstehenden, sondern am Halse herabfallenden Ohren da, sich selber kaum noch ähnlich.

Zwischen dem bösartigen Erysipel und der progressiven Jauchung vermag ich gar keine ätiologischen. Unterschiede aufzufinden, sondern nur anatomische. Unter dem Erysipel sind wir gewöhnt, Hautaffectionen zu verstehen, die sich in der Fläche ausbreiten, aber gar nicht oder sehr wenig nach der Tiefe zu. Unterhalb der Fascien vorkommende subfasciale Processe schliessen wir in das Erysipel nicht ein. Die Fascien bilden aber für die progressiven 
septischen Processe eine Grenze, welche sie wegen der geringen Penetrationskraft der Fäulnissbacterien nicht iberschreiten können. Ist die Fascie also in voller Integrität, eine Commnnication zwischen dem super- und subfascialen Gewebe durch Oeffnungen in-der Fascie nicht hergestellt, und hat der septische Process nicht urspriinglich unterhalb der Fascie begonmen, so wird sich derselbe auch nur oberhalb der Fascie weiter verbreiten, d. h. Erysipelas malignum bleiben. Dieses Erysipelas malignum wird demnach bei jeder frischen Hantverletzung vorkommen können, in welche eine geringe Mienge septischer Substanz aus diesem Stadium hineingelangt oder daselbst sich bildet. Gegen Orth ist hier zu constatiren, dass es gewöhnliche septische Flussigkeiten aus dem phlogo-septogenen Stadium sind, welche das Erysipel erzeugen können, dass es also der Annahme eines Erysipelasgiftes oder Erysipelasbacterien nicht bedarf. Gegen Volkmann ist hier festzustellen, dấss nicht blos palpable Quantitäten putrider Stoffe, sondern auch sehr geringe Quantitäten wirksam sind, wie sie sehr leicht durch Zufall auf Wunden gelangen können. Neben den bisher gewiirdigten Verunreinigungen durch unsaubere Finger und Instrumente, durch Sehwämme und Verbandsmittel, durch Stagnation von Secreten kamn ich nicht umbin, auf eine gar nicht beachtete putride Quelle hinzuweisen, auf die Sputa. In meiner Mittheilung ïber das putride Gift in den Sputis (Centralblatt 1871 Nro. 28) habe ich bereits angefiuhrt, welche intensive Quelle nachweisbar für Fäulnissprocesse in den verschiedensten Sputis vorhanden ist, ohne dass dieses Seeret putriden Geruch zu verbreiten braucht. Es sind mir Fälle begegnet, wo das Cavernensecret Phthisischer, subcutan eingespritzt, nicht blos die stärksten septischen Localprocesse erzeugt hat, obschon es Winter war und das Sputum wenige Stunden vorher expectorirt worden, sondern wo die Intensität der Allgemeinwirkung eine so heftige war, dass das Thier in weniger als 24 Stunden, ja einmal sogar wie nach Blausäure sofort verstarb. Dies Secret war auffallend diinn und daher leicht resorbirbar. In dem gedachten Aufsatze ist nachgewiesen, wie weit verbreitet die Neigung zur Putrescenz in den verschiedensten Sputis ist, in welchen dieselbe gar nicht $\mathrm{zu}$ erwarten war. Diese Quelle putrider Processe ist nicht blos unvermeidlich in unseren Krankenstuben, sondern wir hegen und pflegen sie aus diagnostischen Rijcksichten. Aber auch andere pathologische Secrete werden sich als mögliche Ursachen putrider Vorgänge erweisen, wenn wir nur erst mit zwei irrthümlichen Vorstellungen brechen, mit der, dass jede Fäulniss sich selbst durch deu Geruch 
anzeige und wir daher Fänlniss nur bei faulig riechenden Stoffen zu suchen haben, und mit der anderen noch irrigeren, dass man keine putriden Wirkungen von einem Stoffe zu erwarten habe, der nicht auch an seiner Ursprungsstelle putride wirkt. Cavernöse Sputa brauchen gar keine septogene Einwirkung, weder auf die Caverne noch auf die Bronchialschleimhaut anszuiiben, und doch kann ihr zufälliges Hinübergleiten über einen kleinen Einriss an den Mundwinkeln etc. zu einem recht bösartigen Erysipel fïhren. Dies wird beim nächsten Abschnitt, über Dispositionen und Immunitäten, zur Erörterung kommen.

Während das auf der Haut entstehende Erysipelas malignum in kaum bemerkbarer Weise durch ganz kleine Mengen septischer Stoffe hervorgerufen werden kann, sind bei der progressiven Jauchung der anatomischen Lage wegen die Bedingungen des Eintritts andere. Die Ursache für beide ist ganz dieselbe, das Trauma muss aber zur Entstehung einer progressiven Jauchung entweder das oberhalb und innerhalb der Fascie gelegene Gewebe in gleicher Weise afficirt haben, wie bei den Quetschungen, oder es muss eine Communication durch Oeffnung der Fascie hergestellt sein (penetrirende Wundenl). Dann kann die Sepsis das ganze Glied (Finger, Extremität) in seiner Tiefe ergreifen und die so nicht blos oberflächlich, sondern in toto fortschreitende Sepsis nennen wir progressive Jauchung zum Unterschiede vom Erysipel. Bei offenen Fracturen der Tibia, des Femur, bei offenen Luxationen, aber anch bei subcutanen Fracturen habe ich durch Einspritzung kleiner Mengen von Jauche aus diesem Stadium die progressive Jauchung leicht erzeugt. Es ist bemerkenswerth, dass, wie leicht dies unter den bezeichneten Verhältnissen gelingt, es keineswegs leicht ist, nach Absetzung der Glieder von Amputationsstïmpfen aus progresstve Jauchung zu erzeugen. $\mathrm{Zu}$ diesen und anderen Zwecken habe ich wiederholt Amputationen des Ober- und Unterschenkels bei Kaninchen vorgenommen und den Amputationsstumpf frisch sowohl wie dann täglich mit phlogo-septogenen und septo-pyogenen Stoffen bepinselt, obne dass ich eine progressive Jauchung erzielen konnte. Missfarbige Eiterung, Jauchung am Stumpfe, Verfärbung der Muskelquerschnitte, - aber obschon ich mittelst des feinen Pinsels die Jauche hoch zwischen die Muskelinterstitien einfïhrte, begrenzte sich doch der Jaucheprocess immer eine kleine Streeke oberhalb des Stumpfes. Bis 8 Tage konnte ich solche amputirte Kaninchen nach Oberschenkelamputationen am Leben erhalten, dann starben sie an Septicämie, die Jauchung war nicht bis zum Bauche vorgedrungen. Mir 
scheint hierbei der mangeInde Druck, der leichte allseitige Abfluss der Jauche die Hauptrolle zu spielen und diurfte hierauf auch der giinstige Einfluss der offenen Wundbehandlung trotz ihrer grösseren septischen Gefahr beruhen.

Dass in die Reihe der progressiven septischen Vorgänge aber auch das Erysipelas simplex gehört, liegt uns jetzt zu beweisen ob. Auch hier wieder hat zur Erkennung dieses Zusammenhanges das Kaninchenohr seine unschätzbaren Dienste geleistet, für die ein solch durchsichtiges Organ, das selbst von leiseren Veränderungen Zeugniss giebt, unentbehrlich war. Statt des Erysipelas malignum tritt bei Application septischer Flüssigkeiten auf Nackenwunden unter gewissen Umständen das Erysipelas simplex ein. Dass wir es mit dem Erysipelas simplex zu thun haben, wird aus folgender Beschreibung hervorgehen. Während die Nackenwunde wenig oder gar nicht eitert, oder so verschlossen erscheint, dass selbst ihre Spuren kaum noch nachzuweisen, meist nach 3-4 Tagen, mitunter später erst, selbst am 7. Tage, selten früher, sieht man, wie am Anfang des bösartigen Erysipels, an der Basis des einen oder beider Ohren einen gleichmässig rothen Fleck, der von der Ohrwurzel auf sich in wenigen Tagen ziemlich gleichmässig bis zur Ohrspitze ausbreitet. Die Affection zeigt alle Charaktere einer schwachen Entzündung, wie sie durch Aufpinselung sehr diluirter Säurelösungen und iiberhaupt schwacher Inflammatoria auftreten kömnen. Die Hyperämie ist im Ganzen gleichmässig uiber das ganze Obr verbreitet, doch nicht so kräftig wie wir sie bei directer Einspritzung von Fäulnissstoffen aus dem phlogogenen Stadium beschrieben haben. Dem entsprechend erreicht auch die nachweisbare locale Temperaturerhöhung wie die exsudative Schwellung nicht die höchsten bei Ohrentzündungen vorkommenden Grade. Das Charakteristische dieser in der Art gewandeten Affection bleibt nun, dass nach einigen Tagen wieder vollkommen schwindet, dass Hyperämie und Schwellung aufhören können, ohne eine andere Spur als eine geringe Welkheit des Ohres zurïckzulassen. Wenn die Entziindung: Anfangs nur auf einem Ohre aufgetreten, so kommt es, dass nach Erblassen desselben sie nun erst auf dem andern beginnt. Hin und wieder bleiben als Spuren der Affection ganz kleine wenig prominente Eiterherde an einzelnen Stellen des Ohres zurück, die wie ähnliche andere der allmäligen Resorption anheimfallen würden, wenn die Thiere lange genug lebten. Der Tod tritt aber hier meist, wenn auch mitunter erst Wochen lang nach der Application der septischen Flüssigkeit und lange Zeit nach dem Abblühen des Erysipels an 
dem bisher noch wenig gewürdigten Zustand der chronischen Septicämie ein, ein Zustand, der durch die geringfügigen Localaffectionen oft unerklärbar, bei gutem Appetit der Thiere mit einer allmäligen enormen Abmagerung and consecutivem Kräfteverfall verbunden ist. Das Erysipelas simplex sah ich am häufigsten im septo-pyogenen Stadium eintreten, dann insbesondere, wenn die. Application nicht am ersten Tagie erfolgte. Hatte die Selbstheilung der offenen Wunde bereits zu einer Verklebung derselben geführt, und wurde dieselbe nun gewaltsam aufgerissen und die Aufpinselung der Jauche vorgenommen, am zweiten, auch dritten Tage, dann sah ich, wenn es ïberhaupt noch zum Erysipel kam, dieses gutartige Erysipel anftreten, denn, wie später ausgefïhrt werden wird, ist eine lebhaftere Exsudation der Wunde im Stande, den Eintritt jedes Erysipels hintanzuhalten. Auseinandergezerrte Wunden mit schwacher Exsudation ergeben bei septo-pyogener Einwirkung das gutartige Erysipel.

Es wird nicht überflüssig sein zu bemerken, dass beim Terpentinöl, welches von allen bisher untersuchten chemischen Stoffen am meisten progressive Entziundung erzeugt, der Verlauf derselben von der gleichen Applicationsstelle, der Basis beider Ohren ans, ein wesentlich anderer ist, als in diesen Fällen. Das Terpentinöl vertheilt sich von da aus in der Fläche und Tiefe sehr rasch und bewirkt insbesondere im Unterhautbindegewebe eine sehr kräftige Entziundung mit umfangreicher Schwellung. Am Ohre steigt es nur sehr wenig in die Höhe, präsentirt sich nur an der Ohrwurzel, ohne bis zur Mitte des Ohres, geschweige bis zur Ohrspitze zu wandern. Dabei ist die einmal eingetretene Entzündung nicht' blos von grosser Intensität, sondern auch von längerer Dauer, so dass in Betreff der Wanderung'stähigkeit und Flüchtigkeit diese Affection mit dem Erysipel gar nicht zu vergleichen ist. Insbesondere möchte ich hervorheben, dass bei der Terpentinwirkung von einem 3-4-5tägigen Incubationsstadium gar keine Rede ist, sondern dass der Process die ihm 'mögliche Ausbreitung rasch in weniger als 24 Stunden einnimmt und kaum ïber den occupirten und festgehaltenen Rayon hinausgeht. Alle diese Differenzen erklären sich aus der Verschiedenheit der zu Grunde liegenden Ursache. Die Schwellung der Lymphdriisen am Halse fand ich aber gleich umfangreich, sowohl bei der progressiven Sepsis, als bei der progressiven Terpentinölentzỉndung, den sonstigen Aehnlichkeiten stehen viel grössere Unterschiede gegeniiber. Doch ist die Terpentinölentzïndung die einzige nicht organischen Ursprunges, die iiberhaupt in Betracht gezogen werden kann. 
Die stationären Processe (Jauchung, Eiterung).

Septische Processe bleiben dann stationär, wenn die Bedingungen für das Fortschreiten derselben ungünstige sind. Die guinstigsten Bedingungen ergiebt das lockere subcutane Gewebe, insbesondere dann, wenn durch Dislocationen (Fracturen, Luxationen) Auseinanderzerrungen des Gewebes stattgefunden haben. Dass von Amputationsstiumpfen aus septische Processe geringe Neigung haben progressiv zu werden, ist bereits erwähnt, obschon das Bindegewebe zwischen den Muskeln die Progression befördert. Der Muskelquerschnitt an sich ist für die Fortleitung ungünstig. Dass aber unter pathologischen Verhältnissen auch das Unterhautbindegewebe das Weiterschreiten der Sèpsis hemmen kann, wird im nächsten Abschnitte unter Immunitäten auseinandergesetzt werden.

Blosse Eiterung wird im phlogo-septogenen Stadium selten und nur bei ganz kleinen Mengen, häufig jedoch im septo-pyogenen Stadium erzengt. Mehrmals habe ich die Beobachtung gemacht, dass kleine Jaucheherde von der Luft abgeschlossen und allseitig von Blutgetässen umgeben, wie z. B. in der Wadenmuseulatur, allmälig und in relativ kurzer Frist einen gutartigen Charakter annehmen können. Gleiches geschieht, wenn man faulende Muskelstiucke aus diesem Stadium in eine Nackenwunde bringt und dieselbe durch Suturen schliesst. Mitunter bricht erst nach 14 Tagen die Wunde auf und man findet dann das Muskelstiick von gutartigem Eiter umgeben, von Jauchung keine Spur.

Entziündungen, die noch die Fähigkeit haben, in Resolution überzugehen, habe ich in diesem Stadium nie beobachtet, selbst bei Anwendung minimaler Dosen.

\section{c) Im pyogenen stadium.}

Allmälig geht das septo-pyogene Stadium in das rein pyogene Stadium ïber, in welchem die septische Gangrän im Ohre gar nicht mehr zu erzielen ist und auch der uible Geruch schwindet, mit welchem die Eiterungen Anfangs noch verbunden sind. Starke Eiterungen als Folge der brettartigen Entzündungen, die unter heftigen Gefässerscheinungen (Hyperämie, Hitze) auftreten, charakterisiren diesen Abschnitt der Sepsis. Arch Erysipele kommen noch vor, so lange Bacterien noch nachweisbar sind. Charakteristiseh für dieses Stadium bleibt es, dass während früher $1_{1 / 4} \quad 1 / 3{ }_{3}^{1 / 2} \quad$ C.-C. genügten, um die eigenthümlichen Veränderungen der unmittelbaren oder mittelbaren septischen Gangrän hervorzurufen, jetzt die zweiund dreifache Menge der Flïssigkeit nicht nur nicht mehr ausreicht, sondern dass eine septische Gangrän in ihrer besonderen Form gar 
nicht mehr eintritt. Recht kräftige Eiterungen mit ron Anfang an sehr starken Congestionen sind die Signatur dieses auch wieder auf Monate sich erstreckenden Zeitraumes. In der Form hat die ganze Affection eine unverkennbare Aehnlichkeit mit den Entziundungen, die sich durch nicht septisch wirkende Sputa erzielen lassen.

Ueberblicken wir alle geschilderten Krankheitsformen, so sehen wir, dass wir es mit den Localprocessen zu thun haben, die als Entziundung und Brand auf örtlicher Blutveränderung beruhen. Die Entziindungen haben nichts Eigenartiges an sich, als dass sie unter Unständen eine progressive Tendenz in einem Grade verfolgen, die bis jetzt sonst nirgends beobachtet ist. Von der progressiven Tendenz und dem Geruche abgesehen, der bei stärkeren Exsudationen vorkommt, gleichen diese Entzündungen allen anderen Entzündungen. "Hingegen zeigt die septische Gangrän so viele Eigenthïmlichkeiten, dass sie als besondere Form anderen Brandformen gegienüber anerkannt werden muss.

\section{Immunitäten und Dispositionen.}

Mit der Kenntniss des Verhaltens normaler Stellen gegen die Sepsis der verschiedensten Stadien ist wohl die unentbehrliche Grundlage zur Beurtheilung der septischen Einwirkungen auf den lebenden Organismus gegeben, aber mehr noch nicht. Denn man kann sich nicht verhehlen, dass die Fälle, welche wir im Experimente setzen, relativ selten im Leben auftreten. Wie selten sind die Analogien fuir Blutinfusionen und subcutane Injectionen unter pathologischen Verhältnissen vorhanden! Nur der natürliche Druck der Fascien und der künstliche der Binden und Bandagen erinnert daran, welche Beihtilfe der Druck fur das Eindringen und die Propagation der Sepsis leisten kann. Hiervon abgesehen sind es die offenen Wunden, welche beim Thier wie beim Menschen gleiche Bedingungen darbieten und der Sepsis eine offene Pforte eröffnen. Mit solchen frischen Wunden haben wir es nicht nur bei künstlichen Verletzungen aller Art zu thun, sondern der physiologische Vorgang des Gebäractes pflegt mit gewissen Continuitätstrennungen verschiedener Art sehr oft verbunden $\mathrm{zll}$ sein. Die statistische Häufigkeit der septischen Wochenbettkrankheiten ist bedingt durch die Länge des Geburtskanals und den Umstand, dass alle physiologischen wie pathologischen Absonderungen diesen langen Weg zum Austritt aus den Körper einschlagen müssen, durch die Verletzungen desselben bei den Geburten und durch die Verunreinigung dieser Stellen mit Fingern, Instrumenten und Secreten welche Träger der Sepsis geworden sind. Dieser Complex un- 
ginstiger Bedingungen ist es, welcher diese septischen Erkrankungen in hohem Grade befördert. Auf allen frischen Wunden an allen Körpertheilen werden wir die dem Stadium und der Stärke der septischen Einwirkung entsprechenden Erkrankungen erhalten, die nur je nach den Geweben und den Organen verschiedene Formen und verschiedenen Verlauf annehmen, anders in dem submukösen Gewebe, anders im Peritonäum, anders in den Knochen.

Aber innerhalb des ganzen Wundverlaufes ist doch nur eine ganz kurze Zeit hindurch jede Wunde als frische Wunde zu betrachten und es bleibt daher die wesentliche Frage die, ob auch nicht-frische Wunden der Sepsis eine gleich offene Pforte gewähren, wie dies für jene eben dargestellt worden ist. Wäre dies der Fall, dann wäre bei der langen Dauer der Wundheilungen die Gefährdung derselben eine sehr grosse.

Es ist jedoch in der Praxis lange bereits bekannt, dass derselbe Fäulnissprocess mit pestilentialen Gerüchen auf alten Fussgeschwüren eine für das 'Leben und die Gesundheit des Kranken indifferente Erscheinung ist, der auf einer frischen Wunde in Kurzem den Tod herbeiführen könnte. Auch haben ältere Experimente bewiesen, dass dieselbe Menge fauliger Fliissigkeit, welche, direct in das Unterhautzellgewebe gespritzt, gefährliche, ja letale Folgen hat, nach Erzeugung einer grossen Granulationsfläche gar keine schädlichen Folgen ausübt, ja dass eine solche Fläche täglich mit einer in Jauche getränkten Charpie verbunden werden kann, ohne irgend welche bemerkbare Folgen (Bill roth). Zu erklären versuchte man sich die äussere grobe Thatsache durch die schleimige Beschaffenheit des oft mehrere Linien dicken Granulationsgewebes und die frermeintlich durch die Lymphgefässe erfolgende Resorption der putriden Substanzen. Wie man andererseits geneigt war, die doch zuweilen trotz der Granulation erfolgende Resorption darauf zu schieben, dass die putriden Substanzen zugleich zerstörend oder ätzend wirken, oder eine active Penetrationskraft besitzen, wie Pilze oder Infusorien. Dieser letztere Erklärungsversuch ist offenbar bei dem gegenwärtigen Stande der Dinge hinfällig geworden. Die Anwesenheit von Pilzen ist in jedem Stadium der Fäulniss nachweisbar; besässen sie die ihnen zugeschriebene Penetrationskraft, dann wäre jede Wunde durch sie gefährdet. Aus der Thatsache des häufigen Auffindens von Microsporon septicum in Jauche und in geringer Menge auch in jedem guten Eiter war denn anch Klebs geneigt, ein innigeres Causalitätsverhältniss zwischen Bacterien und Eiter zu statuiren. Drei Eventualitäten sind offenbar in dem Verhältniss zuisehen Bac- 
terien und Eiter möglich. Die erste, dass Sepsis Eiter erzeugt, ist in Beziehung ihrer näheren Bedingungen bereits abgehandelt. Die zweite ist, dass Eiter, irgendwie septisch geworden, seinerseits die Sepsis auf eine frische Wundstelle überträgt. In diesem Falle haben wir lediglich die bisherigen Factoren, die septische Einwirkung auf eine frische Wundstelle, nur dass der Träger der septischen Einwirkung in concreto der Eiter ist, statt der bisher statuirten Muskelflüssigkeit. Dass fauler Eiter auf eine frische Wunde genau wie jeder andere faule Stoff dem Stadium der Sepsis entsprechend wirkt, ist bereits früher von mir dargestellt (die örtliche Wirkung des Eiters und der putriden Stoffe. Centralblatt 1861 Nro. 20). Die Consequenzen sind hier nur um deswillen bedeutendere, weil es wohl kaum einen anderen faulenden Stoff giebt, der so viel Gelegenheit hätte, mit frischen Wunden in Bertihrung zu kommen oder auf dieselben .übertragen zu werden, als faulender Eiter. Zwar, soweit der Eiter sich selbst seine Wege bahnt, trifft er nur selten auf frische Wunden, wo aber künstliche Oeffnungen zu seiner Entleerung nöthig sind, sind auch die neuen Wundkanäle seinem Einfluss schutzlos preisgegeben. Hierauf beruht die empirisch längst bekannte grössere Gefahr künstlicher Oeffnungen gegenüber den spontanen Reifungen und Exfoliationen. Dass Eiter aber an sich leicht fault, ist eine ebenso bekannte als leicht verständliche Thatsache, !ja die meisten offenen Eiterherde stehen geradezu unter den guinstigsten Fäulnissbedingungen. Selbst interstitielle disseminirte Eiterpunkte werden in jeden Fäulnissprocess leicht hineingezogen, wie man sich durch entsprechende Versuche am Ohre schlagend überzeugen kann.

Die beiden bisher behandelten Eventualitäten erklären viele Vorkommnisse im Wundverlauf, aber involviren keine neuen Gesichtspunkte. Ist Eiter, welcher nachträglich septisch geworden, fähig, seinen eigenen bisher nicht septischen Mutterboden septisch zu inficiren? Hier haben wir das Novum, nicht mehr eine frische Wunde, sondern eine Eiter secernirende Stelle vor uns za haben, und da entsteht die Frage, verhalten sich beide Stellen gegenüber der Sepsis gleich? wenn nicht, worin bestehen die Unterschiede? Da jede Wunde nur kurze Zeit frisch ist, so ist diese Frage von grösster Wichtigkeit, kanm eine andere ist practisch von gleich grosser Bedeutung. Erinnern wir uns nun, dass die Sepsis durch die unversehrte Epidermis gar nicht durehzudringen vermag and auf ganz unverletzte Schleimhäute eine äusserst geringfügige Wirkung ausübt, so sehen wir, dass von einer stärkeren Penetrationskraft der Sepsis gar nicht die Rede ist. Folge der geringen Penetrations- 
kraft ist es nothwendiger Weise, dass auch pathologische Hindernisse von der Sepsis nur wenig überwunden werden können. Es sind rein mechanische Verhältnisse, um die es sich hier handelt. Stärkerer Druck kann schwerere Hindernisse überwinden, für den schwächeren sind leichtere selbst schon unüberwindlich. Dies ist das Resultat einer ausgedehnten Untersuchungsreihe. In allseitig geschlossene Abscesshöhlen kann die intensirste Fäulnissflüssigkeit eingespritzt werden, ohne eine Spur von Sepsis zu erregen, gleichgiiltig ob der Eiter noch in der Höhle ist oder bereits ans ihr entleert worden. Je dichter, derber, hautähnlicher die pyogene Membran, desto undurchdringlicher ist dieselbe fur die Sepsis. Ist aber die Wand dïnn und wird sie beim Auspressen verletzt, so entsteht an der durchlassenden Stelle Sepsis, welche von da ab sich weiter fortpflanzen kann. Je allseitiger und fester die gegenseitige Verlöthung der Gewebe ist, und je weniger in den Interstitien der Gewebe die Fäulnissflüssigkeit und mit ihr die Bacterien vordringen können, desto weniger wird die Fortleitung der septischen Processe möglich sein. Alte Abscesswände leisten besseren Widerstand als Pseudomembranen und Adhäsionen, diese mehr, fals blosse Schichten von Eiterkörperchen, aber bei geringem Druck zeigen sich auch diese sufficient. Zum Beweise dessen folgender einfacher Versuch. Macht man eine Nackenwunde an der Basis der Ohren, in oft beschriebener Weise, und bestreicht diese Wunde kräftig mit Petrolenm, dem Mittel, welches ich ron den bisher bekannten als das beste Suppureticum ansehe, so ist die Exsudation nach 3 Stunden natürlich noch sehr schwach, die Wundfläche kaum mehr als wie angehaucht zu nennen. Pinselt man jetzt, also nur 3 Stunden nach Einwirkung des Petroleums, Fänlnissflüssigkeit auf die Wunde, solche, die ohne vorherige Anwendung des Petroleums Erysipelas malignum, ja den Tod selbst zu erzengen im Stande ist, so bleibt diese septische Wirkung ganz aus, die eintretende Eiterung führt bald zu oberflächlicher Verschorfung, unter welcher die volle Heilung der Wunde in kurzer Zeit erfolgt. $\mathrm{Zu}$ bemerken ist, dass das Petroleum kein Antisepticum ist, da die Bacterien in ihm lange ihre Beweglichkeit behalten, die Wirkung kann also nur aúf den inflammatorischen Einfluss des Petroleums bezogen werden. Ob nicht diese Beobachtung: für die Therapie nutzbar gemacht werden kann, soll weiteren Untersuchungen vorbehalten bleiben. - Wir resumiren: Indem die Entzündungen unter Störung der Resorption zu Ausschwitzungen von Flïssigkeiten und Eiterkörperchen, zur Bildung von Eiterschichten, Pseudomembranen und Adhäsionen führen, ändern sie die mechani- 
schen Verhältnisse für das Eindringen der Sepsis sowohl in die Gefässe wie in die Interstitien der Gewebe. Nicht absolute wohl aber relative Hindernisse werden dem Fortschreiten der Sepsis dadurch bereitet, meist sind sie aber bedeutend genug, um die Immunität des Entzündungsherdes gegen die gewöhnlichen Arten der septischen Infection herzustellen.

Unter pathologischen Verhältnissen tritt aber auch andererseits eine Disposition für die Sepsis ein, die der höchsten Beachtung werth ist. Es ist frtiher schon angeführt, in wie hohem Grade der Ejntritt der septischen Gangrän durch Unterbindung der grossen peripheren Arterien (Art. carotis, femoralis für Ohr und Unterschenkel) befördert wird. Der locale Ausgang wird stets durch die Arterienunterbindung verschlimmert.

Dies ist durchaus dem analog, was ich früher bereits über den schädichen Einfluss der arteriellen Anämie mitgetheilt (cfr."Entzündung und Brand, Virchow's Archiv 51. Bd.).

Unter solchen Umständen musste ich die Untersuchung zu der Frage erweitern über den Einfluss hochgradiger Anämie auf den Eintritt der Eiterung. Da das Petroleum in der Menge von 1,0 eingespritzt, wie beschrieben, (die "Genesis der acuten und chronischen Entziindung, Virchow's Archiv 55. Bd.) umfangreiche Eitersäcke producirt, so wurde derselbe Versuch nach Unterbindung beider Carotiden angestellt, numittelbar nachher durch subcutane Injection in eines der beiden Ohren. Gleich nach der Operation sieht man das Ohr ganz blass, nur schwach an der Injectionsstelle von Petroleum getriibt. Nach 24 Stunden bemerkt man bereits eine schwache itio in partes, mit welcher das Weiterfliessen des Blutes abwechselt. Nach 48 Stunden ist dieselbe noch ansgedehnter in den Venen nicht nur, sondern auch in der Arterie zu constatiren. Nach dreimal 24 Stunden pflegt die Blutgerinnung bereits eingetreten zu sein, wobei blaugruine Flecke in der Mitte des Ohres sichtbar werden. Im weiteren Verlaufe erstreckt sich nun die Blutgerinnung mit der gleichmässig grünlichen Verfärbung des Colorits weit über die ursprünglich tangirte Partie auf $2 / 3-3 / 4$ des Ohres, wobei ein eigenthümlicher Geruch auftritt, der, obschon durch den Petroleumgeruch gedämpft und modificirt, doch an schwachen Fäulnissgeruch erinnert. Das äussere Bild hat eine gewisse Aehnlichkeit mit dem Erysipelas maliguum, während beide Krankheiten durch Aetiologie und Verlauf weit von einander liegen. Das Ende ist auch hier Brand und Abtrennung durch Demarcationsentzündung, wie bei anderen Brandformen, wie auch bei der Gangraena septica, 
an die im Uebrigen das ganze Bild am meisten erinnert. Ein ganz gleicher Process tritt ein, wenn bei unversehrter Arteria carotis die in der Mitte des Ohres belegenen kleinen Blutgefässe mit dem entsprechenden Abschnitte der Arteria auricularis mit der Knochenzange zerquetscht werden und sodann die subcutane Injection von Petroleum in diese Stelle hinein vorgenommen wird. Auch hier Ausbleiben der Eiterung, blaugrüne Verfärbung der Stelle, localisirte Gangrän unter gleichem Geruch. Ich glaube, dass man diese $\mathrm{Zu}$ stände, - und ähnliche nicht durch den Einfluss von Bacterien erzengte kommen ja auch beim Menschen vor, - als septoide Zustände von den septischen unterscheiden und ihnen zur Seite stellen muss. Ioh hoffe in Kurzem noch weiteres Material zur Kenntniss dieser septoiden Zustände herbeibringen zu können. Die Disposition der anämischen und der Quetschwunden für Sepsis hat ihre experimentelle Bestätigung: erfahren, diese Fälle treten als gleiche Glieder in eine Kette von Wahrnehmungen ein, welche sämmtlich den hochgradigen bisher unterschätzten Einfluss der arteriellen Circulation auf Entzündung und Brand documentiren.

Durch die in diesem Abschnitt enthaltene Darstellıng der Immunitäten und Dispositionen wird es klar, wie der Sepsis gegenüber pathologisch veränderte Stellen sich vielfach anders verbalten als physiologische. Verletzungen der Blutgefässe in weitem Umfange, Eiterungen und entzundliche Gewebsveränderungen Ider verschiedensten Art sind so häufige Vorkommnisse, dass die Kenntniss des Einflusses der Sepsis unter diesen Umständen ganz [unerlässlich bleibt für die Kenntniss des Wundverlaufes.

Ueber die Erscheinungen, das Herkormmen, die Contagiosität und das Wesen der septischen AllgemeinInfection.

Das Allgemeinleiden bei der septischen Infection besteht in einer tiefen Blutveränderung ohne erhebliche vom Blute ausgehende Localisationen. Während die Infection bei Pocken, Masern, Scharlach rom Blute aus an entfernten Stellen in weit verbreiteten Gefässgebieten der Haut und der Schleimhäute Entzündungen von typischer Dauer hervorbringt, während also - den Bacterienursprung: dieser Krankheiten vorausgesetzt - die Pocken-, Masern-, ScharlachBacterien nach ihrer Proliferation im Blute durch Ansammlung und Wirkung entzündliche Ernährungsstörungen in einzelnen Gefässabschnitten setzen, treten bei der septischen Infeetion derartige Leiden nicht auf. Von der allein etwa hierher zu rechnenden 
Enteritis kann um so mehr abgesehen werden, als sie nach subcutaner Injection sehr selten, sondern immer nur nach directer Blutinfusion auftritt und einen offenbar complexen Ursprung hat. Der locale Zusammenhang der progressiven Processe (Jauchungen, Erysipele) ist bereits besprochen. Symptome der intensiven Bluterkrankung sind neben dem heftigen Fieber, nach anderen nervösen Symptomen, grosse Schwäche, Zittern, Apathie, überhaupt adynamische Zustände, während Krämpfe selten und nicht im Geringsten charakteristisch sind. Diese adynamischen Zustände sind in. Fällen von fulminanter Septicämie sehr rasch zu beobachten, in anderen sub finem vitae. Die chronische Septicämie von 4-5wöchentlicher Dauer ist durch eine ganz enorme Abmagerung charakterisirt, trotz guten Appetits der Versuchsthiere. An frischen Leichen sind sehr geringe Blutveränderungen nachzuweisen, nicht einmal die dunkle Farbe des Blutes und dessen unvollkommene Gerinnbarkeit sind immer zu sehen und bei den von mir applicirten geringen Dosen subcutaner Injection ist es mir weder im Herzblut noch ïberhaupt in entfernten Gefässabschnitten gelungen, eine Proliferation von Bacterien im Blute zu erkennen. Und dennoch erfolgt der Tod.

Wir kommen nun zu der Frage, ob sich bereits die metastatische Pyämie als nichts Anderes, denn als eine modificirte Form der Septicämie erweisen lässt. Metastatische Abscesse waren in keinem unserer Versuche, die sich im Laufe der Jahre auf mehrere Hunderte beliefen, aufzufinden und von den gewöhnlichen Pneumonien, die sich häufiger fanden, war der septische Ursprung nicht mit Sicherheir festzustellen. Nachdem ich die flockigen septischen Gerinnsel bei der Gangrän vor Augen hatte, glaubte ich auch deren Metastase mit Sicherheit erwarten zu dürfen. Ich hoffte, dass jes gelingen würde, die die Metastase verhindernde Demarcationsentzïndung durch Einfuihrung anderer Bedingungen in Wegfall zu bringen. Amputationen grösserer Gliedmaassen schienen aus vielen Gründen dazu geeignet zu sein, aber obschon ich die spritzenden Gefässe der eigenen Blutstillung iiberliess, und demzufolge viele nur durch Thromben geschlossene Gefässlumina täglich mit Jauche bepinseln konnte, obschon durch die längere locale Blutung auch die Kraft des Blutstromes und damit die Energie der Demarcationsentzuindung herabgesetzt war, fand dennoch, wie schon oben angefuihrt, eine Abgrenzung des Jancheherdes unweit oberhalb des Stumpfes statt. Jenseits desselben war weder eine fortschreitende noch eine localisirte Affection in den Venen zu bemerken; die sehr kräftigen Thierexemplare, die allein zu solchen Versuchen benutzt wurden, 
starben nach 8 Tagen bei noch sehr gutem Kräftezustand an Septicämie ohne jede Metastase. In Betreff der Progression der Sepsis in den Venen schien die progressive Jauchung die besten Aussichten zu eröffnen. Fracturen des Oberschenkels mit Verschiebung der Bruchenden, mit Jaucheeinspritzung complicirt, in einzelnen Fällen noch combinirt mit Unterbindung der Art. femoralis unterhalb des Abganges der Profunda femoris hatten Verjauchungen zur Folge, die über den Unterleib hinaus bis zu den Thoraxwänden aufstiegen, aber nichts desto weniger keine Metastasen. Trotzdem erseheint mir seit dem Nachweis flockiger fauler Gerinnsel in den Venen des Fäulnissherdes die metastatische Pyämie als ein so genau in den Rahmen der Krankheit passender Incidenzfall, dass ein Anderer, leicht möglich, gliucklicher hierin als ich, vielleicht bei grösseren Thieren den Transport der Gerinnsel in die Lungen zu demonstriren im Stande sein wird.*) Bis dahin, d. h. bis die Pyämie durch Einführung aller ihrer Bedingungen herzustellen sein wird, ist ihr septischer Ursprung als noch nicht erwiesen zu betrachten.

Für die Entstehung des septischen Allgemeinleidens sind dreierlei Möglichkeiten in Betracht zu ziehen. Das Blut kann dadurch septisch geworden sein, dass von den primär in den Körper hineingelangten Fäulnissstoffen eine gewisse Quote derselben in den allgemeinen Kreislauf übergegangen ist, also durch primüre Resorption. Es könnten zweitens sich neue Fäulnissstoffe am Applicationsherd gebildet haben und so durch locale Reproduction zur Verschlimmerung der Septicämie beitragen, also durch secundäre Resorption. Es könnten aber auch drittens in jedem Abschnitt des Circulationssystems die Bedingungen zur weiteren Fortpflanzung der Sepsis gegeben sein. Hätte die Septicämie allein die erste dieser Quellen, so wäre sie eine blosse Intoxications- und keine Infectionskrankheit, und die zweite Quelle der ersteren hinzugefügt, bliebe es immer noch von dem Umfange der localen Fäulnissherde abhängig, welche Intensität die Allgemeininfection erreichen soll. Erst dann, wenn sic auch auf jenen dritten Ursprung unbegrenzten Anspruch hat, wäre sie wirklich unabhängig von der Grösse des Localherdes, von demselben gewissermassen losgelöst, derselbe wäre kein Mutterboden, sondern nur eine Eintrittsstelle, eine Phase für die septische Allgemeininfection. Dann

*) Wer gleich mir Untersuchungen dieser Art, zumal mit septischen Stoffen in Privaträumen anstellt, ohne Assistenz, ohne völlig Herr seiner Zeit zu sein, durchaus nur auf eigene Hülfsmittel gestützt, kann allein alle Schwierigkeiten einer solchen Arbeit ermessen, Schwierigkeiten, die ganz unüberwindlich werden, wenn es an grösseren Thieren zu operiren gilt. 
würde eine minimale Menge genügen, um den ganzen Körper zu inficiren, die unbegrenzte Vermehrung einer anch noch so kleinen Anzahl von Bacterien im Blute miisste anch die geringste Berührung mit Sepsis zu einer bedrohlichen Gefahr machen.

Dass die primäre Resorption eine Quelle der Septicämie bildet, nach subcutaner Injection septischer Flüssigkeiten, lässt sich auf das Exacteste beweisen. Die Fliissigkeit wird wie die Abnahme ihrer Menge und ihres Colorits beweist, resorbirt, ohne sofort Blutgerinnung zu reranlassen, sie muss also in das Gesammtblut ïbergeführt werden. Je rascher dies erfolgt, wie beispielsweise nach Lähmung des Sympathicus, desto raseher die Allgemeininfection bis zum Tode, desto geringer die Ausbildung der Localphänomene. Die primäre Resorptiou wird also als erste Quelle der Septicämie anzuerkennen sein.

Dass am localen Fäulnissherde die Fäulnissstoffe sich mehren, geht aus den früheren Versuchen bereits hervor. Wenn auch die schwerer beweglichen Gerinnsel demarkirt werden, die flissigen und leicht transportabeln septischen Stoffe sind lange ins Blut hineingeschwemmt, ehe es zur Gerinnselbildung und zur Demarcation derselben kommen kann. Auch diese Quelle fliesst reichlich. In beiden findet die Septicämie Nahrung, aber natürlich nur nach Maassgabe der Localaffection.

Giebt es ntun Thatsachen, welche zwingend sind, um eine von dem Localherde ganz unabhängige Zunahme der Sepsis zu beweisen, mit anderen Worten, ist auch den mit dem Gesammtblute circulirenden Bacterien die Fähigkeit der Selbstvermehrnng zuzuschreiben, sei es, wenn sie sesshaft geworden, sei es im Circuliren selbst? Wäre das der Fall, so miisste im Leben eine Vermehrung der Bacterien im Blute nachweisbar sein; diese ist mikroskopisch nicht zu erweisen. Aber auch die physiologische Reaction zeigt davon keine Spur. Blut einem noch lebenden septischen Thiere entzogen, das aber nur durch subcutane Injection von 1 C.-C. Jauche septisch geworden, resorbirt sich, in ein gesundes Ohr injicirt, wie normales Blut ohne jede Spur einer septischen Localaffection. Aus dieser gleichen Reaction des Blutes septischer Thiere mit gesundem Blute geht schlagend hervor, dass eine bedeutende Zunahme der Bacterien nicht stattgefunden haben liann, ebensowenig wie eine Multplication des septischen Giftes. Welches Schicksal die Bacterien im Blute erleiden, ob sie wie die Farbstoffpartikel begierig von den weissen Blutkörperchen aufgenommen werden (Birch-Hirschfeld), ob sie durch Secrete ausgeschieden werden, ob sie anderweitig untergehen, 
oder ob sie in gewissen hämopoetischen Organen deponirt werden, ist noch nicht festgestellt. Jedenfalls geht aus den bisher bekannten T'hatsachen eine selbstständige Vermehrung der Fäulnissbacterien im Blute; unabhängig vom Fäulnissherde, nicht hervor.

Die Frage über die Contagiosität der Fäulniss beantworten wir nach unseren Versuchsresultaten in folgender Weise:

1) Contagiös sind die örtlichen Producte der Sepsis, der septischen Gangrän vor voller Vertrocknung; der Jauchungen etc. und zwar je nach dem Maasse der vorgeschrittenen Sepsis und wie immer nach der Stelle, auf welche sie wirken. Das frither angeführte Beispiel der Sputa beweist, dass sich selbst Septicaemia fulminans dureh örtliche Producte der Sepsis erzielen lässt. Die localen Blutveränderungen sind unter :ortliohe Producte der Sepsis innebegriffen.

2) Selbstverständlich wird das Blut auch im Leben contagiös sein können, wenn dasselbe seinerseits Locus affectionis geworden ist, d. h. wenn die septische Flüssigkeit direct in grösseren Mengen in

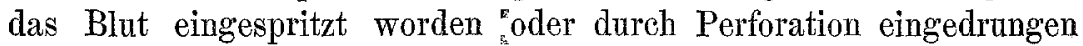
ist und sich so einer grösseren Blutmasse beigemischt hat. Auch hier wie im vorigen Falle vermögen bereits minimale Mengen, wie sie unbeachtet an Instrumenten und Fingern haften können, einen verderblichen Einfluss auszuiiben.

3) Hingegen ist es nicht nachweisbar, dass nach blossen subcutanen Injectionen das Blut solcher Thiere im Leben bereits septisch wirkt. So wenig sich ein solches Thier selbst inficirt, wenn es an andern Stellen Entziundung bekommt, so wenig ist es geeignet, andere Thiere zu inficiren, wie oben bereits dargelegt.

4) Nach dem Tode solcher Thiere zeigt sich hinwiederum das Blut contagiös, da mit dem Tode die Hemmung fortfällt, welche während der Circulation des Blutes der Fäulniss entgegenwirkt. Von den Nebenumständen, der Zeit die nach dem Tode verflossen, der Wärme, welcher der Cadaver ausgesetzt war und ähnlichen Verhältnissen wird es abhängen, welche septische Kraft das Blut entfalten kann, ebenso wie der septisehe Muskel sie ausübt.

Geht man mit diesem Maassstabe der Contagiosität an die Davaine'schen Versuche, so wird man die Bestätigung wie die Nichtbestätigung derselben zu würdigen wissen. dium der fulminanten Septicämie sehr kleine Mengen, - von den Trionteltropfen wollen wir dabei absehen - den Tod bringen können, so wird in geeigneten Fällen dies anch mittelst eines. Tropfens septischen Blutes möglich sein. Schon zu Anfang wurde ja erwähnt, 
dass anch der todte Muskel eines septischen Thieres das phlogogene Stadium ganz überspringen kann und sofort septogene Wirkungen zu erzeugen im Stande ist, wie viel mehr wird dies mit septischem Blute der Fall sein, welches dem blos putriden Blute im Fäulnissstadium immer voraus sein wird. Aber von directer Blutinfusion abgesehen, kommt diese Contagiosität keineswegs dem septischen Blute im Leben zu, noch lässt sich eine Potenzirung des Giftes im Körper irgendwie nachweisen. Machte ich unterschiedslos subcutane Injectionen von Blut septischer Thiere, so gelang es mir nicht, die Contagion auf 3 Glieder fortzupflanzen, viel weniger auf 25, während man bei geeigneter Auswahl die Contagion wohl iiberträgt, von der bei Sepsis sehr schwer nachweisbaren Potenzirung aber nichts bemerken kann. Bei der Contagiosität wie bei anderen septischen Fragen sind Zeit und Umstände entscheidend, weshalb eine Vereinigung der Einzelfälle zu verschiedenen Gruppen geboten ist. Ganz unstatthaft ist es gerade hier, alles zusammenzuwerfen und einzelne Erfahrungen zu generalisiren; solchem Verfahren widerspricht die ganze Natur der septischen Infection.

Sollen wir nach alledem die eigentliche Natur, das Wesen der septischen Infection bestimmen, so lässt sich die complexe Fäulnisswirkung in drei von einander zu trennende Wirkungen spalten.

1) Die specifisch septische Giftwirkung ist durch flüchtige Sloffe (Schwefel- und Ammoniakverbindungen) bedingt. Dies lässt sich dadurch beweisen, dass, wenn stark übelriechende Jauche einem Warmwasserbade von $60^{\circ} \mathrm{R}$. unter fleissigem Umrühren mehrere Stunden hindurch ausgesetzt wird, die nahezu geruchlos gewordene Flïssigkeit jetzt keine septische Gangrän mehr erzeugt, wohl aber noch progressive Processe, als sprechender Beweis dafür, dass die im Warmwasserbade ruhig gewordenen Bacterien ihre Lebens- und Fortpflanzungsfähigkeit nicht eingebüsst haben. Die Gangrän, die blaugrüne Färbung derselben und ihr Fäulnissgeruch sind als chemische Wirkungen zu betrachten und nicht als organische. In gleicher Weise kann der an fulminanter Septicämie. erfolgende Tod nur als Vergiflungstod angesehen werden, da die ihrer flüchtigen Giftstoffe beraubten Bacterien einen derartigen Tod nicht mehr zu veranlassen vermögen, ebensowenig wie sie noch die septische Gangrän zu producirén im Stande sind.

2) Die progressive Wirkung ist die Leistung der Bacterien, welche durch ihr Leben, ihre Theilung und ihre Wanderung Propaganda mit den Stoffen machen, deren Träger sie sind. Darin besteht ihre Wirkung auch im lebenden Organismus, sie pflanzen sich 
namentlich in den Interstitien der Gewebe fort und wandern weiter in ihnen, während im lebenden Blute für ihre Weiterentwickelung Hindernisse bestehen, deren Natur noch nicht erkannt ist. Aber auch in den Geweben, in denen sie sich fortgepflanzt, rufen sie, wenn sie nicht Träger septischer Stoffe sind, nur Entzündungserscheinungen hervor, nie Fäulniss. Erst wenn die septischen Stoffe der localen Blutcirculation ein Ende gemacht haben, erst dann können sie gleiche Wirkung ausuiben auf Leben wie auf Tod. Ist ihnen das Gift genommen, dann haben sie für den lebenden Organismus nur die Bedeutung als Entzündungserreger. Eine wie ganz andere unbeschränkte Herrschaft üben sie im Tode aus, unvergleichlich mit dieser. so vielfach eingeengten, in welcher die Formen der Bacterien nicht einmal zu der freien und mannigfachen Entwickelung. gelangen können, die ihnen sonst eigen ist.

3) Ist durch mehrstündiges Kochen und nachträgliche Filtration die Jauche sowohl ihres septischen wie ihres Bacterien-Gehaltes beberaubt, so wirkt die noch übrig gebliebene Flüssigkeit noch immer phlogo- und pyrogen, wenn auch die Entzündungsform zu den Resolutionsentzünduugen gehört, die weder zu Gangrän noch zu Eiterung: tendiren. In der Flüssigkeit sind also noch chemische, nicht flïchtige und nicht organische Stoffe gelöst, welche als schwache Inflammatoria anzusehen sind.

In systematischer Untersuchung studirten wir die Wirkung eines faulenden Stoffes von Beginn des Fäulnissprocesses bis zu seinem Ende. Welche Fülle von Erscheinungen, von Modificationen, von Wechsel in diesem einen Falle! Werden alle Fäulnissprocesse einander rollkommen identisch sein? Dies ist mehr behauptet als bewiesen, als es auch nur wahrscheinlich ist. Wohl mancher Krankheitsstoff verbirgt sich noch jetzt unter dem weiten Mantel des organischen Fäulnissprocesses. Weiter aber und viel weiter hinaus wird die Experimental-Pathologie die Aufgabe zu übernehmen haben, einen jeden thierischen Infectionsstoff ausserhalb des Körpers in geeigneter Nährflüssigkeit zu ziichten und seine Wirkungen von seiner Blïthe bis zu seinem Untergange festzustellen, eine Aufgabe, die für alle angestrebt werden muss, für wenige vielleicht vollkommen zu erreichen sein wird. Doch jeder Schritt auf diesem systematischen Wege ist folgenreich und schafft neue Einsicht für die eigentlichsten Aufgaben unserer Wissenschaft.

Bis für Diphtherie, Milzbrand, Recurrens, Pocken, Masern und Scharlach, Cholera und Typhus die Entstehung and Fortpflanzung: 
der Krankheitsursachen, die Eintritts- wie die Hemmungsbedingungen, die Mechanik ihrer Wirksamkeit im Körper bis zu ihrem Schwinden klar und offen vor der Wissenschaft daliegen werden, wird mehr wie eine Generation von Forsehern dahingehen, für das grosse geistige Erbe der Menschheit gilt ja aber das Wort:

„Multi pertransibunt et augebitur scientia." 